\title{
Carbon nanotubes and nanotube composites for nonlinear optical devices $\dagger$
}

\author{
Jun Wang, ${ }^{a}$ Yu Chen ${ }^{b}$ and Werner J. Blau ${ }^{* a}$ \\ Received 30th March 2009, Accepted 9th July 2009 \\ First published as an Advance Article on the web 10th August 2009 \\ DOI: $10.1039 / \mathrm{b} 906294 \mathrm{~g}$
}

Carbon nanotubes possess not only outstanding mechanical, electrical and thermal properties but also unique nonlinear optical properties. In this Feature Article, we review the recent developments of the carbon nanotube and its composites for nonlinear optical applications. Two research hot spots are discussed: optical limiting for laser protection and the saturable absorber as a mode-locking component for ultra-short pulsed lasers. The physical mechanism, materials and devices are intensively introduced for each application. All of the investigations indicate that the carbon nanotube is one of the main competitive candidates for next generation of photonic components.

\section{Introduction}

Nonlinear optics, which studies the interaction of intense light field with matter, is a relatively new field in physics with lots of fundamental scientific and technological potential. ${ }^{1-3}$ Generally speaking, all materials including gases, liquids and solids, can exhibit nonlinear optical (NLO) responses under high intensity light illumination, the magnitude of which is determined by their intrinsic properties. By distinguishing the origin of nonlinearity, the NLO materials can be divided into molecular materials (e.g. organic molecules, organic crystals and polymers) and bulk

${ }^{a}$ School of Physics and the Centre for Research on Adaptive Nanostructures and Nanodevices (CRANN), Trinity College Dublin, Dublin 2, Ireland. E-mail: wblau@tcd.ie; Fax: +3531896 2151; Tel: +35318961708

${ }^{b}$ Key Lab for Advanced Materials, Department of Chemistry, East China University of Science and Technology, 130 Meilong Road, Shanghai 200237, China

$\dagger$ This paper is part of a Journal of Materials Chemistry theme issue on organic non-linear optics. Guest editor: Seth Marder. materials (e.g. inorganic crystals, metals and semiconductors). The nonlinearity in the former is determined by the structure of the individual molecules, while in the latter the nonlinearity is related to the electronic characteristics of the bulk materials.

Following the rapid development of nanotechnology in the past few decades, a large number of nanomaterials have been shown to possess remarkable NLO properties, which motivates the design and fabrication of nano and nano-scale photonic and photoelectronic devices. ${ }^{4}$ The most representative products of nanotechnology are carbon-based nanomaterials: from 3D carbon black or nanoparticles, ${ }^{5,6}$ to $0 \mathrm{D}$ fullerenes, ${ }^{7,8}$ to $1 \mathrm{D}$ carbon nanotubes (CNTs), ${ }^{9-12}$ and then to $2 \mathrm{D}$ graphenes ${ }^{13,14}$ discovered most recently. In addition to the outstanding mechanical, electrical and thermal properties, ${ }^{15-18}$ the unique NLO properties of CNTs have generated much research interest from both experimental and theoretical aspects. ${ }^{9-12,19-21}$

In this Feature Article, we review the recent development of pristine and functionalized nanotubes for NLO applications.

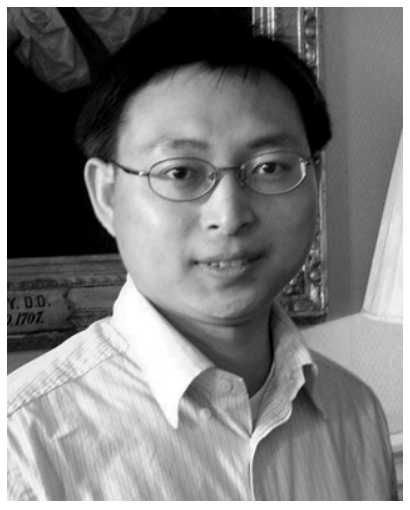

Jun Wang
Jun Wang currently is a postdoctoral research fellow in Prof. Werner J. Blau's group at Trinity College Dublin. He was awarded his PhD degree in materials science and engineering from the Chinese University of Hong Kong in 2006. His research interests focus on nonlinear optics of nanomaterials, organic and inorganic microcavity lasers and photonics of sol-gel materials. So far he has published more than 20 peer-reviewed journal papers in Adv. Mater., Appl. Phys. Lett., Opt. Lett., J. Phys. Chem. C, etc.

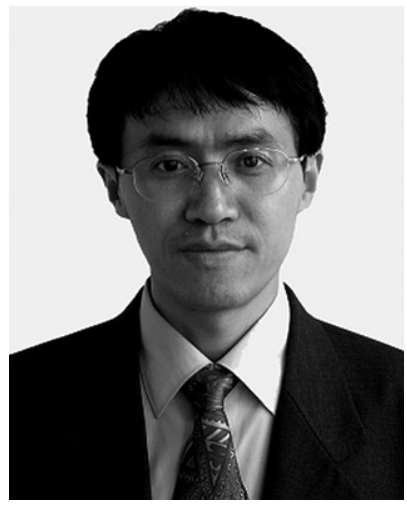

Yu Chen
Yu Chen is full professor at East China University of Science and Technology, Shanghai. He received his PhD in Organic Chemistry at Fudan University in 1996. From July 2000 to June 2002, he worked in Prof. Dr Michael Hanack's group at the Institute of Organic Chemistry, University of Tuebingen, as Alexander von Humboldt research fellow. His research interests include organic synthesis; organic andlor polymeric functional materials designed for nonlinear optics, OLED/PLED, solar cells, and molecular memory devices; fullerene chemistry; phthalocyanine chemistry; and photoinduced electron transfer processes of conjugated polymers. He has published more than 120 papers in international peer-reviewed journals. 
Before the detailed discussions, it is interesting to note in Fig. 1 the $Z$-scan curves of CNT dispersions ${ }^{22}$ and sprayed films. ${ }^{23}$ $Z$-scan is a simple but powerful technique to characterize the NLO properties of materials, including nonlinear absorption, scattering or refraction. ${ }^{24}$ In this method a laser beam is focused by a convex lens to create an intensity-spatially-varied optical field. When an optical material is moved around the focal point along the $z$-axis, one can readily obtain information on the variation of transmission against incident intensity, and hence the nonlinear parameters of interest. As shown in Fig. 1a, the total transmission of nanotubes in liquid dispersions decreases as the intensity of the incident beam is increased. That is to say, the nanotube dispersions can effectively suppress the higher intensity light but allow high pass for the lower intensity light. On the contrary, in Fig. 1b the transmission of the CNT films increases as the incident power increases, i.e. the nanotube films can largely eliminate the low-intensity background noise resulting in the enhanced high-intensity signal. Regardless of the different laser sources used, the different nonlinear responses in Fig. 1 reveal two important applications of CNTs: optical limiting for laser protection and saturable absorber as a mode-locking element for ultra-short pulsed lasers. It is the CNT, a versatile material, which exhibits alternative nonlinear responses for different requirements. In the next two sections we discuss systematically the mechanisms, materials and devices of these two applications.

\section{Optical limiting}

Following the invention of the laser, it was recognized that intense laser beams can easily damage delicate optical instruments, especially the human eye. Nowadays, lasers have become common in daily life, so much so that they are being incorporated into toys. Thus, protection from lasers is not only a scientific subject but also a potential public safety issue. ${ }^{11,25}$ The protection of such instrumentation has led to comprehensive and extensive

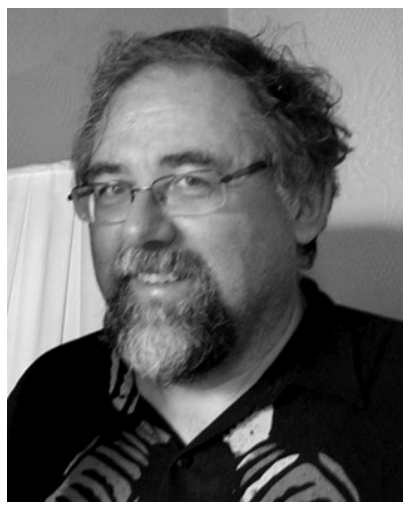

Werner J. Blau
Werner J. Blau is Professor of Physics of Advanced Materials in School of Physics, Trinity College Dublin. His interdisciplinary group encompasses researchers from the fields of physics, chemistry, engineering, and computer simulation with a substantial track record in technology transfer and collaboration with Irish industry. His research interests concentrate on molecular engineering of advanced materials, properties and applications of molecular and polymeric materials for electronics, optoelectronics, and bio/medical applications and basic materials, processes and devices for molecular nanoelectronics and bionanotechnology. He has published over 380 papers (over 7000 citations and h-index 42), edited three books and coauthored 14 patents or applications.
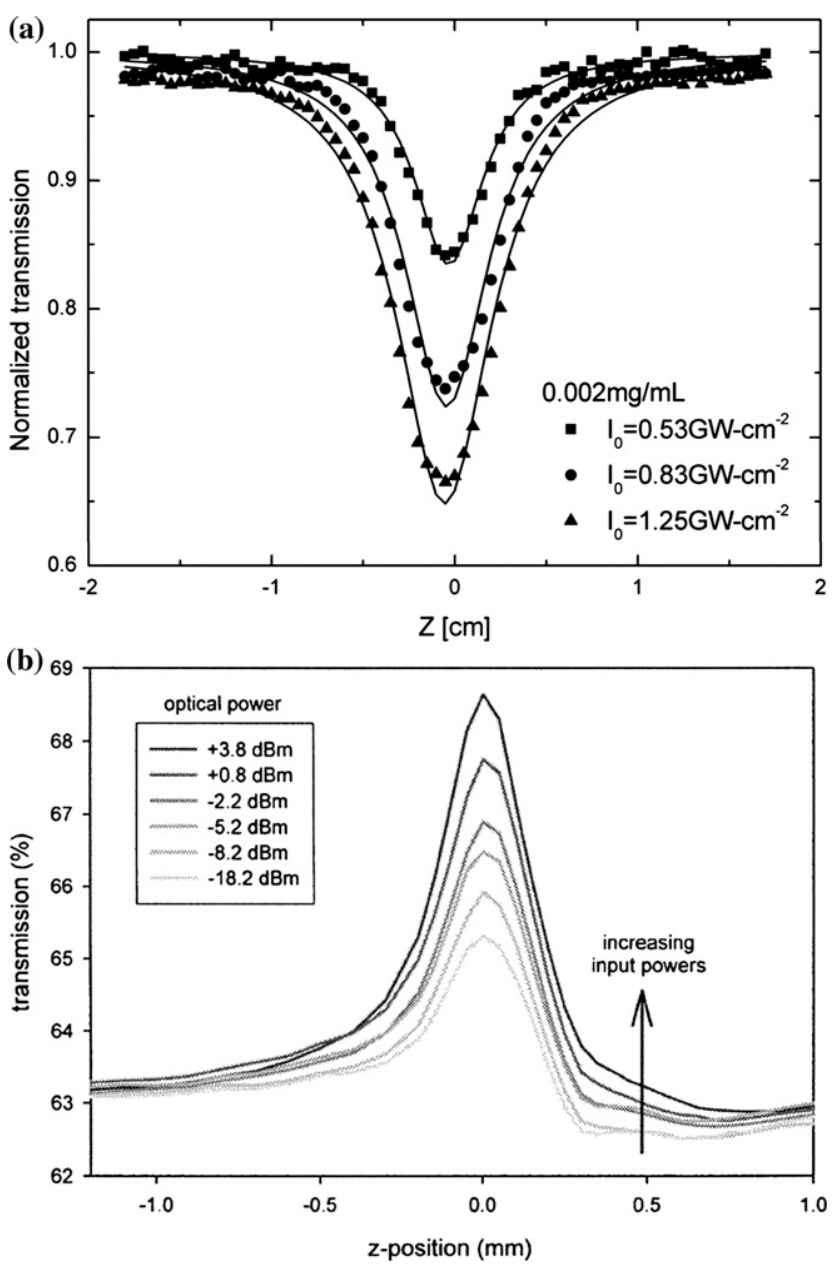

Fig. 1 Typical open aperture $Z$-scan data with normalized transmission plotted as a function of sample position $Z$. (a) Nanotube dispersions for nanosecond laser pulses at $532 \mathrm{~nm}^{22}$ and (b) nanotube films for picosecond laser pulses at $1550 \mathrm{~nm} .{ }^{23}$

research in the field of optical limiting. Fig. 2(a) illustrates a concept response of optical limiters. A successful optical limiter should strongly attenuate intense and potentially dangerous laser beams, while exhibiting high-transmittance for low-intensity ambient light. Up to now a number of organic and inorganic materials, including fullerenes, ${ }^{7,8,26}$ phthalocyanines, ${ }^{27-30}$ porphyrins, ${ }^{31,32}$ inorganic nanoparticles ${ }^{12,33,34}$ and metal complexes and clusters ${ }^{35}$ have exhibited strong nonlinear extinction (viz., absorption and/or scattering) for high-intensity light and hence could be considered as viable optical limiting materials. In the past decade, CNTs have been extensively studied as an optical limiting material. ${ }^{9-12}$ It is appealing that the nanotubes combine the advantages of the other two allotropes - carbon black has broadband optical limiting and the fullerene acts as a favourable counterpart for functional materials. CNTs exhibit a significant optical limiting effect covering a broad wavelength range from the visible to the near infrared (NIR). Most importantly, the advantage of nanotubes manifests itself in tailorable chemical properties by binding functional materials, e.g. metal nanoparticles, organic molecules and polymers, forming versatile optical limiting composites. ${ }^{\mathbf{1 2}}$ 


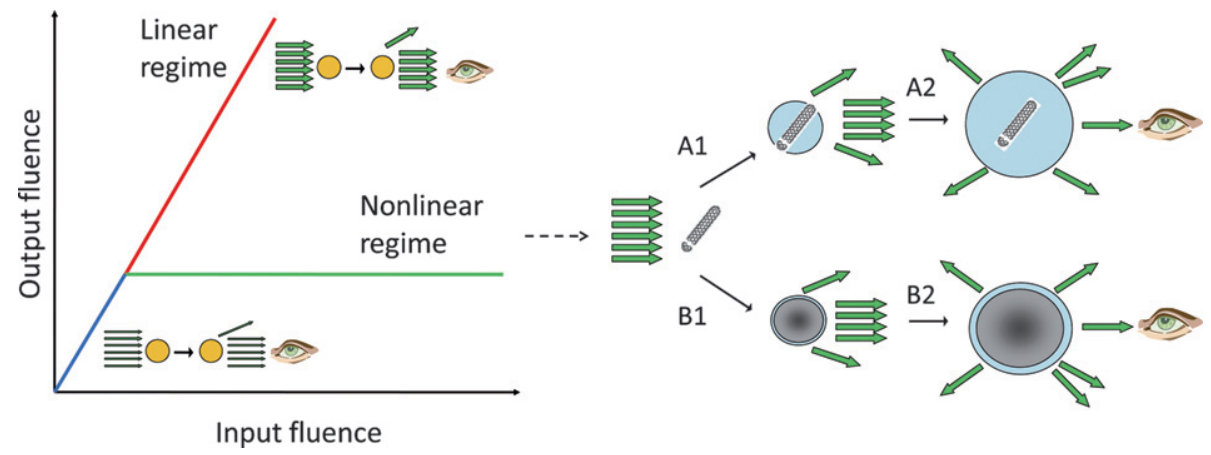

Fig. 2 (Left) The response of an ideal optical limiter. (Right) Illustration of the formation of scattered centers in CNT dispersions. A1: nanotubes absorb the incident laser energy and transfer the thermal energy, hence the surrounding solutions are evaporated, resulting in the formation of gas bubbles with nanotube nuclei; A2: the initial bubbles expand quickly due to the large pressure difference at the vapor-solution interface. When the size of bubbles grow to the magnitude of the incident light wavelength, the bubble clouds can effectively scatter the incident beam, resulting in the reduction of transmission; B1: nanotubes could directly be ionized by the high intensity laser pulses, forming microplasmas; B2: the fast expansion of microplasmas results in the formation of scattered centers, followed by the attenuation of the incident beam.

\subsection{Mechanisms}

There exist two main mechanisms that constitute optical limiting: nonlinear absorption (NLA) and nonlinear scattering (NLS). ${ }^{12,36}$ Based on different materials and absorption mechanisms, the former can be divided into: multi-photon absorption (MPA) (organic molecules, crystals, quantum dots, etc.), ${ }^{37}$ reverse saturable absorption (RSA) (fullerenes, phthalocyanines, porphyrins, etc.) ${ }^{\mathbf{8}, 28,31}$ and free-carrier absorption (FCA) (i.e. semiconductor nanoparticles, metal nanocomposites, etc. $){ }^{33,34}$ The NLA-based optical limiting materials generally dominate fast response time in the picosecond (ps) regime, while the response spectral region is relatively narrow due to the limit of the resonance wavelength. Scattering may play the most common role for the optical phenomenon involved in nanomaterials. ${ }^{12}$ In the scattering process, the high intensity beam is dispersed in order to have larger spatial dimensions and, hence, a reduction in the intensity is achieved. According to the Mie scattering theory, the light beam cannot be effectively scattered by nanoscale particles alone. The effective scattering must come from the formation of scattering centers, the size of which is in the order of the wavelength of the incident laser beam. In general, the induced dynamic scattering centers originate from: the generation of solvent bubbles, the ionization of nanoparticles and the refractive index discontinuity due to the thermal effect of the solvents surrounding the nanoparticles. The scattered intensity from such Mie scattering centers is not sensitive to the incident wavelength, resulting in a broad response wavelength region.

The mechanism leading to the optical limiting effect in pristine nanotubes has been investigated by many researchers., ${ }^{98-44}$ Thermally induced NLS is generally accepted as the principal mechanism for optical limiting. As illustrated in Fig. 2(b), the induced scattering centers consist of two origins: the formation and growth of solvent bubbles, which is due to the thermal energy transfer from the nanotubes to the solvent; and the formation and expansion of carbon microplasmas, which is due to the ionization of nanotubes. The former takes place at the lower incident energy fluence, while the latter takes place at higher fluences. The Mie scattering theory was applied by Vivien et al. to model the extinction scattering profile in nanotube suspensions. ${ }^{44}$ The evolution of the size and concentration of scattering centers in suspensions were estimated by assuming that the solvent/carbon vapour bubbles are uniform spheres and neglecting multiple scattering. Experimentally, the scattering angular profile with the characteristics of Mie scattering was observed by O'Flaherty et al. from CNT/polymer dispersions, where the multi-walled CNTs possess long rodlike cylindrical structures. ${ }^{45}$ However, to the best of our knowledge, there still is a lack of a full theoretical description of NLS in nanotube suspensions. Belousova et al. developed a theoretical model to explain the optical limiting of carbon nanoparticles. ${ }^{46-48}$ In this model, the whole limiting process is described theoretically by three steps: the dynamics of the formation and expansion of solvent vapour bubbles; the Mie scattering of the expanding bubbles; and the nonlinear propagation through the scattering medium. Although the objects of modeling are quasi-spherical carbon nanoparticles, the Mie theory-based prediction works qualitatively for nanotubes and is helpful for understanding bubble growth dynamics and thus the optical limiting process in CNT suspensions. For instance, one can tell the inside pressure, expansion rate and radius of gas bubbles as functions of illumination time; the onset time of boiling, temperature and radius of gas bubbles as functions of illumination energy density. Fig. 3 illustrates the changes of the absorption and scattering cross

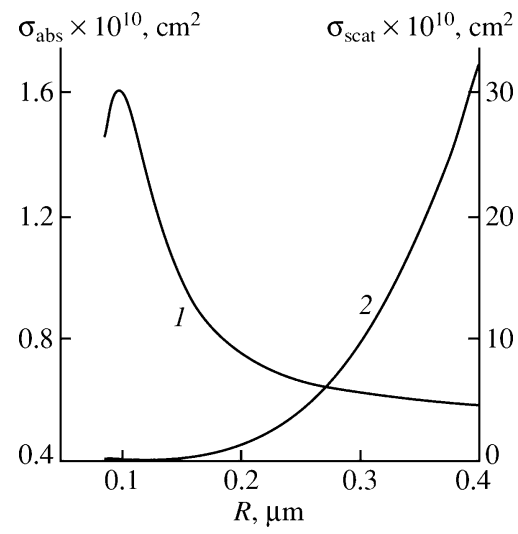

Fig. 3 Variations of (1) absorption and (2) scattering cross sections as radius of gas bubbles in carbon nanoparticle suspensions. ${ }^{46}$ 
sections of carbon nanoparticles as functions of the bubble size after Belousova's simulation. ${ }^{46}$ The scattering cross section increases significantly with the increasing size of vapor bubbles, meanwhile the absorption cross section decreases until it is negligible when the bubbles grow, effectively limiting the incident power.

One usually evaluates the optical limiting performance of CNTs by comparing it with some standard nonlinear materials, e.g. $\mathrm{C}_{60}$. However the comparison results appear to be inconsistent. For example, Vivien et al. demonstrated that the singlewalled nanotube suspensions in water/surfactant have better optical limiting responses than those of $\mathrm{C}_{60}$ solutions. ${ }^{49}$ Meanwhile, Mishra et al. observed the superior optical limiting responses from $\mathrm{C}_{60}$ solutions rather than those from singlewalled nanotube suspensions in water. ${ }^{40}$ The above-mentioned results reveal that the optical limiting properties of CNTs can be influenced by many effects, such as bundle size, solvent property, wavelength, pulse width of incident laser, etc. Table 1 summarizes the factors that influence the optical limiting performance of nanotube suspensions. There are two intrinsic parameters affecting optical limiting: the structure of the CNTs and the thermodynamical properties of the solvent used to disperse the nanotubes. Whereas the length of nanotubes has relatively less of an effect on the optical limiting properties the bundle diameter has been proven to have strong influence. ${ }^{50,51}$ Provided that the bundle diameter keeps constant, the nanotubes with longer length or larger aspect ratio exhibit a better NLO response. ${ }^{52,53}$ The nanotubes with the largest bundle size have the biggest initial scattering centre size, more effective heat transfer from nanotubes to solvents, and hence the fastest solvent bubble growth, resulting in the lowest limiting threshold and the best limiting efficiency. It is difficult to distinguish which is the best material for an optical limiter: single-walled nanotubes or multi-walled nanotubes. For the both, the crucial effect for optical limiting is still the diameter size, rather than their specific structures. Furthermore, the thermodynamical properties of the solvents make a significant contribution to the limiting performance of nanotube suspensions. For instance, nanotubes, dispersed in a solvent with a lower boiling point, show a lower limiting threshold and a better limiting effect; ${ }^{40}$ the heat-induced solvent bubbles grow much faster in a solvent with lower surface tension, thus the bubbles can reach the critical size in a shorter time for effective scattering, resulting in a faster limiting response. ${ }^{50}$ In addition, nanotubes possess better optical limiting performances with an incident beam with shorter wavelength, longer pulse duration, ${ }^{39,54}$ as well as lower repetition rate, ${ }^{55}$ which can be easily explained by the thermally induced NLS mechanism. Overall, we can tell from Table 1 that all of the effects tightly correlate with the dynamic process of the scattered centers.

\subsection{Materials}

Carbon nanomaterials contribute a lot to optical limiting applications. Carbon black suspensions (CBSs), carbon nanoparticles, fullerenes, and CNTs all exhibit a remarkable nonlinear extinction effect with intense laser beams. As we mentioned above, the optical limiting performance of nanotubes can be improved by functionalization with metal nanoparticles, organic molecules and polymers. In this subsection, we introduce some representative works on CNTs and functionalized nanotube composites for optical limiting.

Following the investigation of CBSs for optical limiting, people started to realize that the CNT could be a new class of carbon nanomaterial for optical limiting in 1998. The research groups at the National University of Singapore reported for the first time the optical limiting property of nanotube suspensions. ${ }^{9,38}$ The broadband optical limiting response was demonstrated using nanosecond (ns) laser pulses and NLS was proposed as the primary mechanism for optical limiting. In addition, the wavelength, solvent and bundle size effects were considered in their works. Fig. 4 shows the nonlinear responses of a mixture of nanotubes, nanoparticles and $\mathrm{C}_{60}$ at different wavelengths. It clearly tells us the difference between NLSdominated nanotubes/nanoparticles and RSA-dominated $\mathrm{C}_{60}$ : as the exciting laser light moves towards the longer wavelength region, the nonlinear response from $\mathrm{C}_{60}$ vanishes gradually, whilst the nanotubes still exhibit effective optical limiting effect. As shown in Fig. 4(a), the nonlinear transmission of the CNT suspension has a distinct discontinuity, corresponding to a limiting threshold. The transmission is roughly constant when the energy fluence is below the threshold. When the incident fluence exceeds the threshold, the transmission decreases significantly. The limiting threshold implies that the nanotubes transfer enough heat energy to the surrounding solvent to cause the solvent to vaporize and grow to the critical size, in order to effectively scatter the incident beam. In contrast, the transmission of the $\mathrm{C}_{60}$ decreases with increasing incident energy. There is no evidence of the limiting threshold for $\mathrm{C}_{60}$ in the

Table 1 Summary of the factors that influence the optical limiting responses of CNT dispersions. The signs of inequality indicate the contrast of optical limiting responses

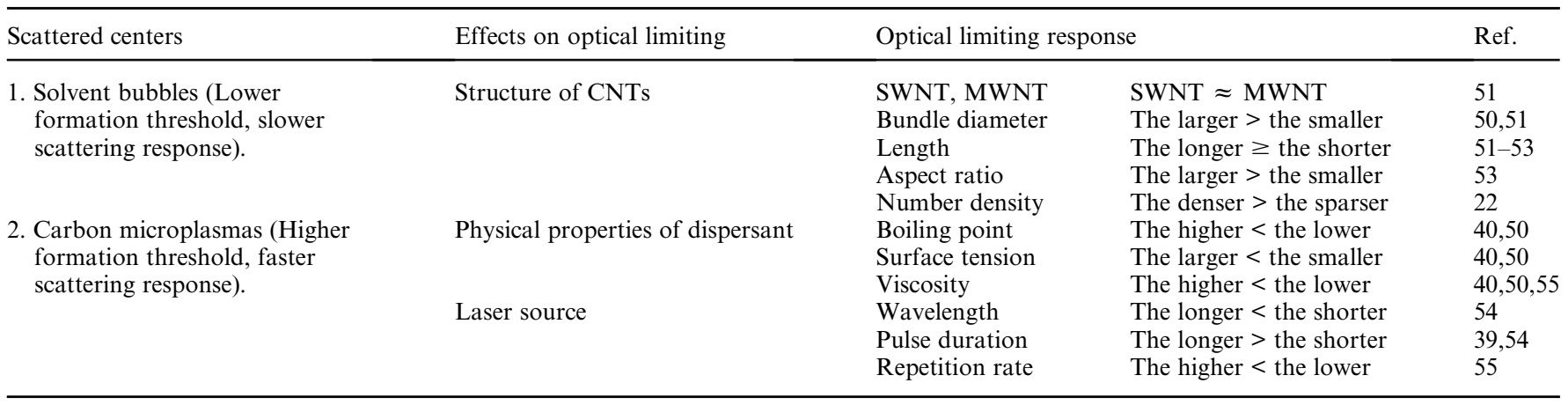




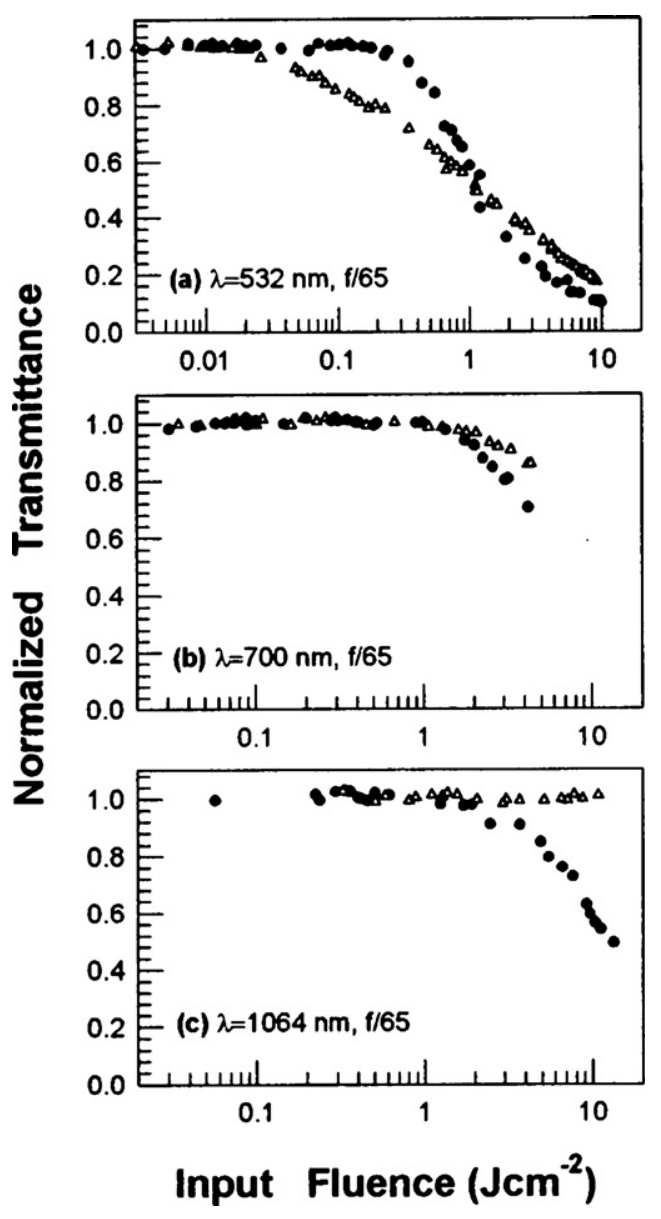

Fig. 4 Optical limiting responses of a mixture of nanotubes and nanoparticles $(\bullet)$ and $\mathrm{C}_{60}(\triangle)$ at different wavelengths. ${ }^{38}$

figure. Similar results were observed by Wang and Blau. ${ }^{22,50}$ Vivien et al. studied systematically the optical limiting performance, dynamics and mechanism of CNT suspensions by employing a series of experimental methods, e.g. Z-scan, the time-resolved pump-probe technique, white light emission measurement, the nonlinear transmittance experiment and the shadowgraphic imaging technique. ${ }^{10,41-44,49,54,56}$ Solvent bubble growth and the phase transition of CNTs at a range of incident fluences were observed, which confirmed that NLS, arising from solvent bubble and carbon vapour bubble formation, dominates the NLO properties of CNT suspensions. The impact of the incident beam wavelength and pulse duration on the optical limiting performance has been studied as well. ${ }^{54} \mathrm{Fig}$. 5 illustrates the typical transmission of the probe beam in ns timescale, where the decreased transmission of the probe beam is due to the scattering of gas bubbles. At lower incident intensities the onset of the decrease occurs after the pump pulse, implying the absence of optical limiting. In contrast, the drop in transmission takes place earlier and is located in the pump pulse under higher intensity excitation, resulting in effective optical limiting. One can actually simulate the growth dynamics of these bubbles in suspensions by monitoring the decreasing trace of the probe, further estimating the size and concentration by Mie theory. ${ }^{44}$

CNTs tend to aggregate into large bundles due to the high surface energy, which is a serious obstacle when it comes to real-

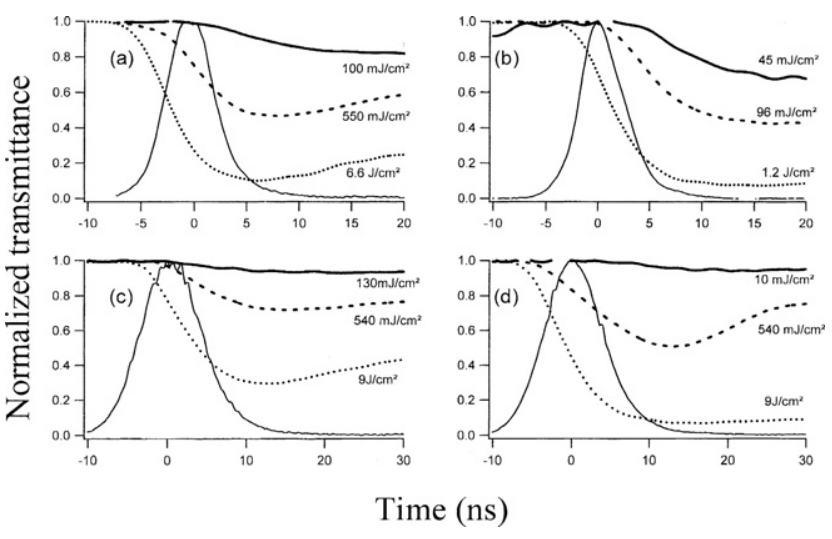

Fig. 5 Transmission of the probe beam as a function of time for singlewalled nanotube suspensions in water (a) and chloroform (b) at $1064 \mathrm{~nm}$ and in water (c) and chloroform (d) at $532 \mathrm{~nm}$. The pump pulse profiles are shown in solid lines as well. ${ }^{10}$

life applications. People have found that CNTs can exist stably as individual nanotubes or small bundles in a range of amide solvents for reasonable periods of time. A typical example is the demonstration of large-scale debundling of single-walled nanotubes by diluting nanotube dispersions with the solvent $\mathrm{N}$ methyl-2-pyrrolidinone (NMP). ${ }^{57}$ Experimental and theoretical analyses reveal that the surface energies of NMP and some other solvents, i.e. $\mathrm{N}, \mathrm{N}$-dimethylacetamide (DMA) and N,N-dimethylformamide (DMF) match very well with that of the nanotube. This results in a minimal energy cost to overcome the van der Waals forces between two nanotubes, and hence the effective debundling. ${ }^{58}$ Wang and Blau investigated the NLO properties of individual nanotubes in NMP, ${ }^{22}$ where the population of individual nanotubes was observed to increase as the concentration is decreased, with up to $\sim 70 \%$ of all dispersed objects being individual nanotubes at a concentration of $4.0 \times 10^{-3} \mathrm{mg} \mathrm{ml}^{-1}$.

Atomic force microscopy measurements reveal that the rootmean-square diameter of nanotubes decreases to less than $2 \mathrm{~nm}$ at $8.0 \times 10^{-3} \mathrm{mg} \mathrm{ml}^{-1}$ before saturating at this level. Even with smaller sizes, the individual nanotubes still exhibit superior optical limiting performance for $532 \mathrm{~nm}$ ns pulses than phthalocyanine nanoparticles ${ }^{59}$ and $\mathrm{Mo}_{6} \mathrm{~S}_{4.5} \mathrm{I}_{4.5}$ nanowires. ${ }^{60}$ According to the well-calibrated size distribution of nanotubes, one could deduce the linear and nonlinear extinction coefficients for a single nanotube. Improved optical limiting performance was found from the same nanotubes in DMF. ${ }^{50}$ As shown in Fig. 6, the DMF dispersions show superior nonlinear extinction effects and lower limiting thresholds. The static light scattering proved that the DMF dispersions have the larger average bundle size, which in combination with the lower boiling point and surface tension of DMF, results in the superior optical limiting performance.

Most of the optical limiting studies on pristine nanotubes concentrate on the physical mechanism and its influencing factors as summarized in Table 1. Although pristine nanotubes possess broadband limiting effects, the nanotubes alone could not satisfy all requirements for laser protection. The development of complex CNT composites is expected to enable practical optical limiting devices. Whereas a lot of organic dyes exhibit NLA at certain wavelength bands, the optical limiting effect in nanotubes 

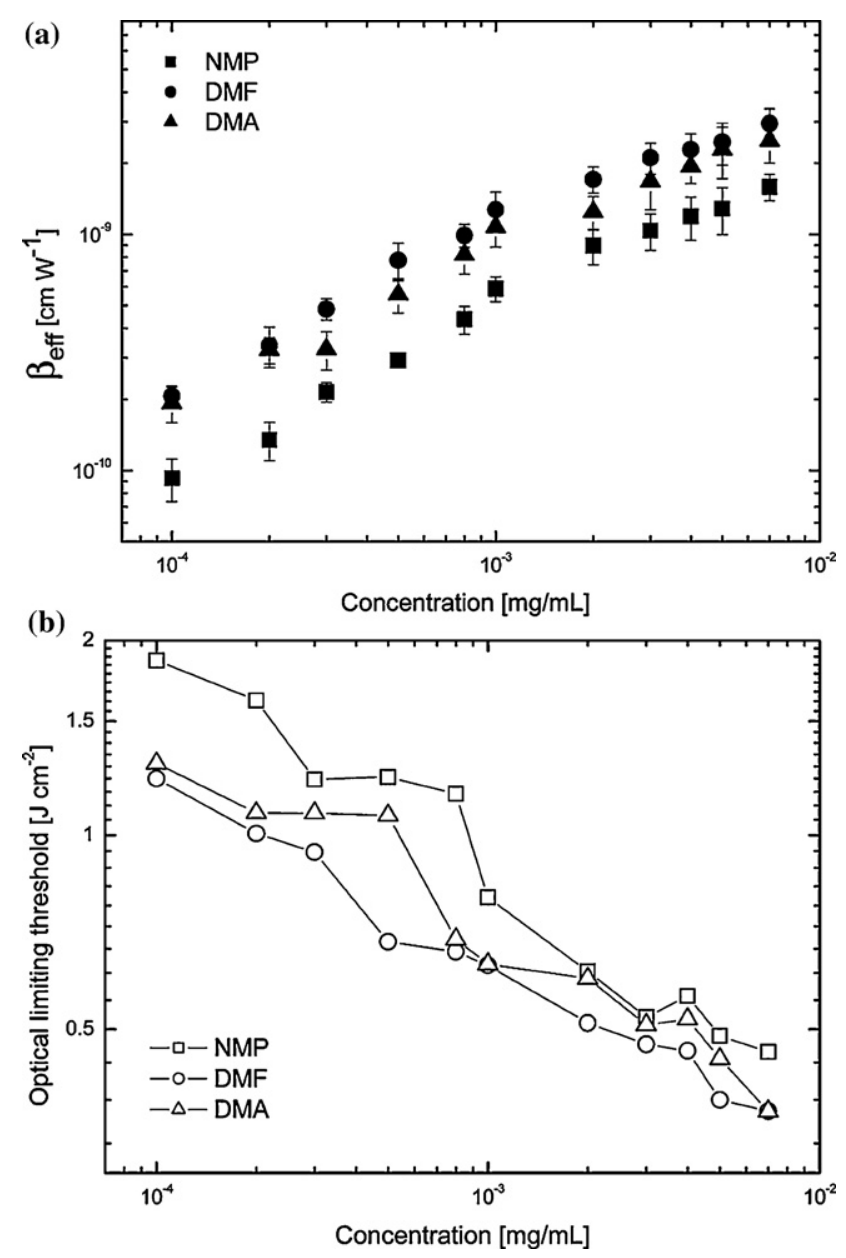

Fig. 6 The nonlinear extinction coefficient (a) and optical limiting threshold (b) as functions of single-walled nanotube concentration for NMP (squares), DMF (circles), and DMA (triangles) dispersions. ${ }^{50}$

covers a broad wavelength range from the visible to the NIR. Nonlinear absorbers, i.e. phthalocyanines, have a quick response time in the ps regime, while nanotubes generally respond at best in the ns regime. ${ }^{61}$ Merging the complementary temporal and spatial nonlinear characteristics of NLA compounds and nanotubes has resulted in the development of nonlinear absorber-CNT hybrids by covalent or noncovalent link.

A two-photon absorption chromophore, Stilbene-3, and a single-walled nanotube mixture was prepared by Izard et al. ${ }^{62}$ The cumulative optical limiting effect was observed when the two moieties have comparable optical limiting responses. If one moiety dominates, the whole optical limiting performance is close to that of the moiety. The composites, which exhibit both NLS and MPA, are expected to work in a broad temporal and spectral range. It should be mentioned that in order to optimize the NLS effect the authors were resigned to avoiding the adsorption of the chromophore on the nanotube, which could delay the formation of solvent bubbles. Webster et al. blended a RSA dye, 1,1',3,3,3',3'-hexamethylindotricarbocyanine iodide (HITCI), with functionalized nitrogen-doped multi-walled nanotubes to enhance the nonlinear transmittance of the whole system. ${ }^{63}$ The blended composite exhibits an improvement in the optical limiting performance in comparison with the two

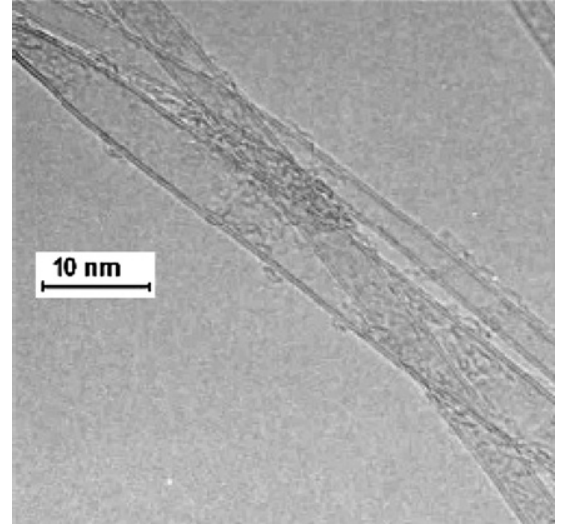

Fig. 7 TEM image showing the adhesion of organic porphyrin molecules to the outside of double-walled nanotubes. ${ }^{64}$

individual materials. At the low intensity regime, the nonlinear response is dominated by the RSA dye HITCI before the NLS becomes significant. After the onset of NLS at the high intensity regime, nanotubes dominate the optical limiting. Blau and co-workers demonstrated the superior optical limiting effect from a noncovalently linked tetraphenylporphyrin-nanotube composite. ${ }^{64}$ The transmission electron microscope (TEM) image in Fig. 7 shows clearly the adhesion of porphyrin molecules to the outside of double-walled nanotubes by van der Waals interaction. The photo-induced electron transfer effects from covalently or noncovalently linked RSA dye-nanotube composites have been widely studied, ${ }^{65,66}$ which may help to improve the NLO response of such complex material systems. Very recently, Wang and Blau reported the linear and NLO properties of a range of phthalocyanine-nanotube blends. ${ }^{61}$ The authors observed that the addition of nanotubes did not change the linear UV-visible absorption characteristics of phthalocyanines but resulted in significant fluorescence quenching. Due to the solvent effect, the phthalocyanine-nanotube composites in DMF exhibit a larger nonlinear response than those in NMP. As shown in Fig. 8, the blends enhanced the optical limiting performance in the higher

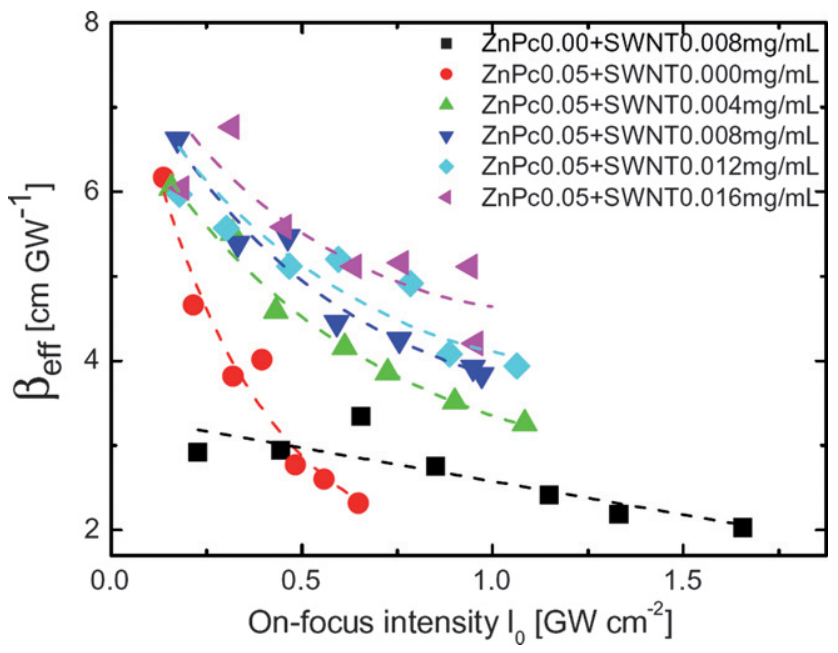

Fig. 8 The effective nonlinear extinction coefficient as a function of onfocus intensity for various phthalocyanine-nanotube composites in DMF. The dashed lines are intended as a visual guide. ${ }^{61}$ 


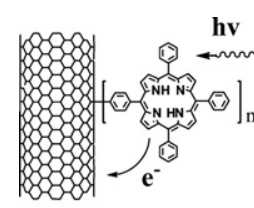

SWNT-TPP (I)

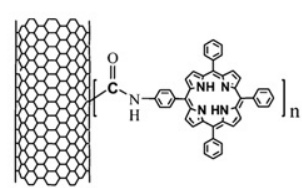

SWNT-NH-TPP (II)

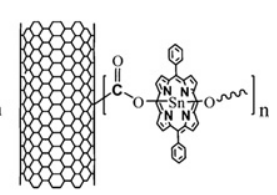

SWNT-SnDPP (III)

Fig. 9 The structures of the covalently-linked porphyrin-nanotube composites. ${ }^{68}$

energy density region when compared to the phthalocyanine solutions. In agreement with Webster et al.'s result, ${ }^{63}$ phthalocyanines influenced the optical limiting effect in the lower energy density region, while the nanotubes played a more critical role in the attenuation of incident laser light in the higher energy density region. Overall, the optical limiting behaviour of the composites was increased with further addition of nanotubes. Apart from the noncovalently-linked dye-nanotube composites, de la Torre et al. described the synthesis and characteristics of covalently functionalized single-walled nanotubes with metallophthalocyanines ${ }^{67}$ Recently, Liu et al. synthesized covalentlylinked porphyrin-single-walled-nanotube composites. ${ }^{68}$ The structures of the porphyrin-functionalized nanotubes are illustrated Fig. 9. Compared with $\mathrm{C}_{60}$, individual nanotubes and porphyrins, the composite solutions show outstanding optical limiting responses for ns laser pulses at $532 \mathrm{~nm}$. The authors attributed the superior performance to the effective combination of the NLO mechanism and the photo-induced electron transfer between porphyrins and nanotubes. In the same vein, a multiwalled CNT composite covalently functionalized by $\pi$-conjugated metal-free phthalocyanines was synthesized by Chen et al. for optical limiting applications. ${ }^{69}$

The optical properties of CNTs can be modified by coating functional composites. Chin et al. successfully improved the transmission of nanotubes in the near UV region by coating silicon carbide or silicon nitride on the surface. ${ }^{70}$ The high transmission nanotube composites incorporated with good optical limiting performances are appropriate for the development of laser protection devices. The same authors further employed polycrystalline $\mathrm{Au}$ or $\mathrm{Ag}$ nanoparticles as coatings deposited on the outside of multi-walled nanotubes. ${ }^{71}$ Typical scanning electron microscope (SEM) images for various coated nanotube composites are shown in Fig. 10. Broadband optical limiting effects for ns pulses at $532 \mathrm{~nm}$ and $1064 \mathrm{~nm}$ were demonstrated in the functionalized nanotube composites. Enhanced limiting performance for $532 \mathrm{~nm}$ pulses was observed from the composites when compared with pristine nanotubes. The surface plasmon absorption (SPA) of $\mathrm{Au}$ and Ag coatings at $532 \mathrm{~nm}$ is attributed to the enhancement of the NLS as well as the optical limiting effect in the nanotube composites. However, polycrystalline $\mathrm{Ni}$ - and Ti-coated nanotubes did not show significant improvement for optical limiting since Ni and Ti nanoparticles do not exhibit SPA around $532 \mathrm{~nm}$. Moreover, it should be mentioned that the CNT and carbon nanoparticle mixtures were studied as a class of optical limiting nanomaterial as well. ${ }^{38,72}$

As we mentioned above, the large surface energy of CNTs imposes restrictions on the formation of individual nanotubes in most inorganic and organic solvents. For solubilized nanotubes, one can employ organic molecules or polymers to functionalize,
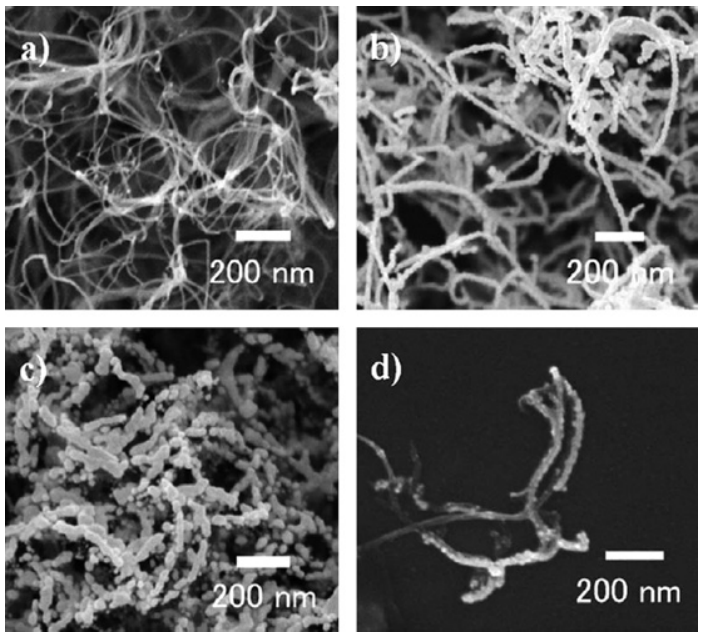

Fig. 10 SEM images for (a) multi-walled nanotubes, (b) Au-coated nanotubes, (c) Ag-coated nanotubes and (d) Au-coated nanotubes after ultrasonication. $^{71}$

covalently or noncovalently, the surface of nanotubes. ${ }^{73-75} \mathrm{~A}$ breakthrough in exploring the noncovalent interaction of the nanotube and polymer was made by Curran et al. who adopted a conjugated polymer, poly(m-phenylenevinylene-co-2,5-dioctoxy-p-phenylenevinylene) (PmPV), to disperse and purify the nanotubes, resulting in property modified nanocomposites. ${ }^{76}$ The coiled polymer conformation allows it to surround the layers of the nanotubes, permitting sufficiently close intermolecular proximity for $\pi-\pi$ interaction to occur. The PmPV has a bright yellow color while the PmPV-nanotube composite possesses a deep green color, implying the strong interaction between the polymer chains and the nanotubes. As shown in Fig. 11, a clear wrapping effect of individual nanotubes by the PmPV matrix was

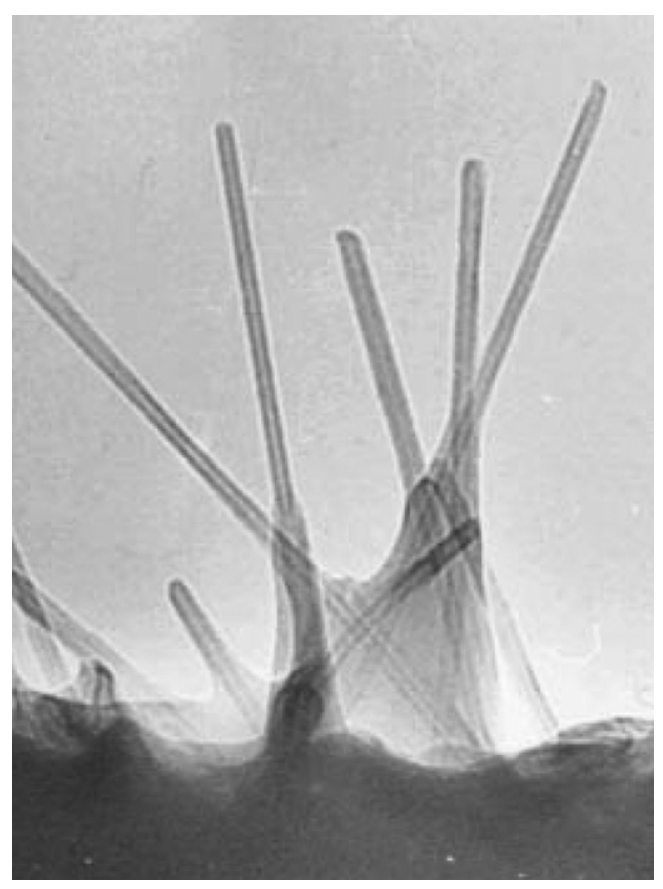

Fig. 11 TEM image of nanotubes in PmPV. ${ }^{76}$ 
observed by TEM. PmPV is an appropriate polymer for the dispersion of CNTs while retaining the superior optical response from the nanotubes. O'Flaherty et al. synthesized two kinds of polymer-nanotube composite by dispersing nanotubes into $\mathrm{PmPV}^{72}$ and poly(9,9-di-n-octylfluorenyl-2,7'-diyl) (PFO) ${ }^{45}$ respectively. Both of these composite systems showed an excellent optical limiting effect on ns laser pulses at $532 \mathrm{~nm}$. The strong back and front scattered light signals, with characteristics of Mie scattering, indicate evidence of the NLS origin of optical limiting. Jin et al. chose a range of conjugated polymers (i.e. poly(2-vinylpyridine), poly(4-vinylpyridine), poly(4-vinylphenol) and poly(ethylene oxide)) to blend or graft with multi-walled nanotubes for optical limiting application. ${ }^{77}$ The physically blended polymer-nanotube composites exhibited a comparable optical limiting performance to chemically grafted polymernanotube composites for $532 \mathrm{~nm}$ ns pulses. The former possess apparent advantages due to their simple preparation procedure. Riggs et al. synthesized soluble CNTs by utilizing poly(propionylethylenimine-co-ethylenimine) to attach it to nanotubes or functionalized nanotubes by octadecylamine. ${ }^{52}$ Compared with nanotube aqueous suspensions, the homogeneous nanotube solutions in chloroform showed an inferior optical limiting effect for $532 \mathrm{~nm}$ pulsed laser irradiation due to the smaller particle size and different solvents in question. Benefiting from the rapid development of soluble CNTs and nanotube composites, a number of soluble nanotube systems were investigated for optical limiting as well as other NLO applications. Liu et al. demonstrated broadband optical limiting effects from didecylamine and octadecylamine modified nanotubes, both of which exhibited similar NLO responses to $\mathrm{C}_{60} \cdot{ }^{78}$ $\mathrm{Xu}$ et al. prepared polyurethane-urea-nanotube composites by the sol-gel method..$^{79}$ The nanotube concentration dependent optical limiting effect for $532 \mathrm{~nm}$ ns pulses was found. Li et al. employed conjugated polymer polyacetylenes to functionalize CNTs. ${ }^{80}$ The hybrid system can emit visible light while limiting high intensity pump pulses. Polystyrene or poly(methyl methacrylate) (PMMA) functionalized nanotube systems were synthesized by Wu et al. ${ }^{81,82}$ The material systems have very good solubility in common organic solvents and exhibit a superior optical limiting performance than the pristine nanotubes. Very recently, Wang et al. reported the optical limiting property of a multiple hydroxyl groups direct-modified-nanotube-carbonnanotubol. ${ }^{83}$ From the above examples, we notice that whatever nanotubes were chemically bound or physically coated by polymers, the nanotubes alone act as the optical limiting material. It reminds us that if doping the soluble nanotubes into polymers with large two-photon absorption cross section, ${ }^{37}$ the whole system possesses both NLS and MPA, undoubtedly resulting in an improved optical limiting performance.

\subsection{Discussion}

The following comments should be pointed out for CNT-incorporated optical limiting:

(1) Since pristine nanotubes mainly possess NLS, most of the nanotube-incorporated NLO materials exhibit the NLS effect. Although some papers only reported the optical limiting property at a single wavelength, say, $532 \mathrm{~nm}$, it is believable that most of the NLS-dominated nanotube systems have a broad response wavelength for optical limiting. Whereas the optical limiting effects up to $1064 \mathrm{~nm}$ were frequently reported for various nanotube systems, the limiting property at wavelengths larger than $1064 \mathrm{~nm}$ has not been reported so far. With the restriction of the nature of NLS, the nanotube systems work effectively for laser pulses from ns up to millisecond durations. To realize the power limitation of ultra-short pulses from the ps to the femtosecond (fs) regime or a low intensity continuous wave laser beam, one must employ functional materials to integrate with CNTs.

(2) Aiming for applicable optical limiting devices, an apparent disadvantage involving nanotube systems is that NLS only exists in liquid solutions. While introducing such NLS effects into a solid state matrix is a big challenge, the development of optical limiters with liquid nanomaterials will be an engineering issue. Since the limiting property of the CNT system is very sensitive to the material structure and the environmental properties, as shown in Table 1, one can finely control and engineer the whole NLO response for specific optical limiters. ${ }^{84}$ On the other hand, NLS can coexist with various NLA mechanisms, which broadly extends the freedom for designing versatile optical limiters.

(3) For functionalized CNT materials, there are two types of status in which the nanotube and its functional moiety coexist. In the first type, nanotubes are treated separately from the functional dopants. It is readily expected that the NLS effect from nanotubes can coexist very well with the NLA from the functional materials and little conflict between the NLS and NLA would take place. In the second type, the nanotubes interact with the functional molecules or polymers by covalent bonds or noncovalent van der Waals forces. In this case, the two moieties would have some conflicting effects due to the different optical limiting mechanisms. ${ }^{61}$ Recalling Fig. 3, the absorption is largely suppressed when the scattering becomes significant. Nevertheless, the ps quick response from NLA materials and the ns response from the nanotubes could coincidentally avoid such a conflict.

(4) It is worth mentioning that the NLO property has been studied for a new carbon allotropy, graphene, a hexagonally symmetric, covalently bonded 2D carbon monolayer. ${ }^{13}$ Very recently, Wang et al. prepared a series of unoxidized and defectfree graphene dispersions with large populations of single and multilayer graphenes by employing high-yield exfoliation of graphene in the liquid phase. ${ }^{14,85}$ The graphene dispersions exhibit broadband optical limiting for ns pulses at 532 and 1064 $\mathrm{nm}$. Nonlinear scattering, originating from the thermally induced solvent bubbles and microplasmas, is responsible for this nonlinear behaviour. The surface tension of the solvents has a strong influence on the optical limiting performance of the graphene dispersions. Overall, graphene flakes exhibit a similar optical limiting response to that of $\mathrm{C}_{60}$ and single-walled nanotubes. In the same way that $1 \mathrm{D}$ CNTs serve not only as nonlinear scatters but also as host material for functional counterparts, this unique 2D nanomaterial could be a promising host for an optical limiter as well as for other photonic devices. A porphyrin functionalized graphene composite was synthesized by Xu et al. ${ }^{86} \mathrm{The}$ soluble graphene nanohybrid exhibits an improved optical limiting performance compared with $\mathrm{C}_{60}$. A combination of multiple nonlinear mechanisms, i.e. RSA, MPA, NLS, as well as photoinduced electron transfer was proposed for the enhanced NLO response. In addition, the optical limiting property of 
graphene oxide (GO) in DMF was studied by Liu et al. ${ }^{87}$ The RSA and MPA are responsible for the NLO response of GO solutions under ns and ps pulse illuminations at $532 \mathrm{~nm}$ respectively. As with CNTs, the demonstration of graphene for optical limiting renders graphene and related materials as a new class of nanomaterial for photonic and optoelectronic nanodevices.

\section{Saturable absorber}

As we know, laser and nonlinear optics always complement each other. The invention of the laser hastened the delivery of nonlinear optics from theoretical prediction to experimental observation. Incorporating NLO components into a laser cavity inversely controls and modifies the output performance of lasers. Whereas numerous inorganic and organic materials, with unique NLO properties, have been frequently used to realize Q-switching or mode-locking for lasers, nanomaterials are rarely found to participate in the modulation of laser until the emergence of CNTs as saturable absorbers. ${ }^{88,89}$ In this section, we introduce CNTs as practical and efficient broadband NLO materials with applications in ultrafast pulse generation and control.

\subsection{Mechanism}

Laser sources producing ns to sub-ps optical pulses are a major component in the portfolio of leading laser manufacturers. They are deployed in a variety of applications ranging from basic scientific research to plastic material processing, from eye surgery to printed circuit board manufacturing, from metrology to the trimming of electronic components. Regardless of the wavelength, the majority of ultrashort (ps-fs) laser systems employ a mode-locker, i.e. a NLO element-called a saturable absorber-that turns the laser continuous wave output into a train of ultrashort optical pulses..$^{90-92}$ Fig. 12 illustrates schematically the working principle of a passively mode-locked laser

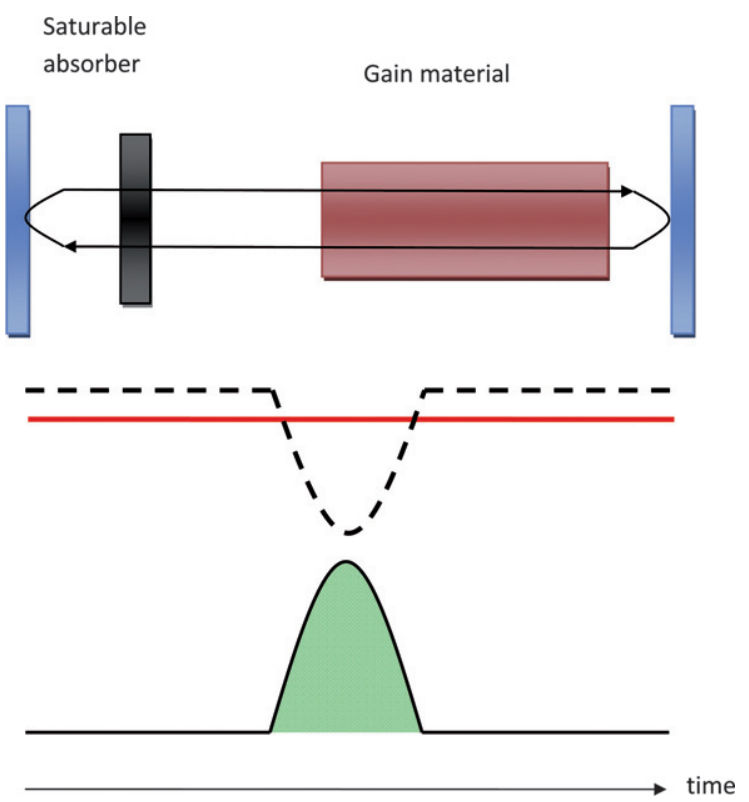

Fig. 12 Schematics of the cavity structure of a passively mode-locked laser with a fast saturable absorber, the temporal modulations of loss and gain and waveform of generated pulse. with a fast saturable absorber. In the laser cavity, the total gain remains constant while the total loss is modulated by the saturable absorber. The gain is always smaller than the loss in the low intensity regime. When the loss is reduced to be smaller than the gain in a very short time window, the net gain becomes positive, resulting in the generation of a pulse with a duration comparable to that of the window. The fast modulation of loss is realized by the instantaneous absorption change of the saturable absorber. Recalling Fig. 1(b), the saturable absorber exhibits an intensitydependent absorption: the higher the incident intensity, the lower the absorption. Thus, the loss can be decreased significantly when the signal is improved. In addition, it is essential for a fast saturable absorber that the recovery time must be shorter than the pulse duration.

Compared with the active mode-locking technique, passive mode-locking can generate much shorter pulses, resulting from the faster loss modulation by a saturable absorber. The key requirements for nonlinear saturable absorber materials are; fast response time, strong nonlinearity, broad wavelength range, low optical loss, high power handling, low power consumption, low cost and ease of integration into an optical system. The currently available solutions do not meet all of these needs. In the present technology, saturable absorbers frequently use multi-quantum well semiconductor heterostructures as saturable absorbers, in the shape of a Semiconductor Saturable Absorber Mirrors (SESAM). ${ }^{93}$ Their fabrication involves well established, but costly and often environmentally aggressive growth and packaging procedures. Each design has a relatively small bandwidth (of the order of $100 \mathrm{~nm}$ ), covering a narrow wavelength range $(\sim 800-1600 \mathrm{~nm})$. CNT and nanotube-polymer composites have the potential to overcome all the shortcomings of traditional technology. CNTs only consist of carbon atoms and can be thought of as a layer of graphite rolled up into a cylinder. Their electronic properties depend on their diameter and chirality, i.e. the twist angle along the tube axis, which can be defined by two integers indicating the chiral vector. One can compute the energy versus $1 \mathrm{D}$ electronic density of states (DOS) of CNTs using the tight-binding zone-folding method. ${ }^{94}$ Semiconducting tubes have a band gap which varies inversely with their diameter. Their DOS and absorption spectra consist of a series of strong 1D singularities. Fig. 13(a) illustrates the DOS for a $(10,0)$ zigzag semiconducting single-walled CNT, where the sharp peaks denote the van Hove singularities. As indicated by the arrows in Fig. 13(a), the electronic transitions between the valence bands and conduction bands (viz., $\mathrm{v}_{1} \rightarrow \mathrm{c}_{1}, \mathrm{v}_{2} \rightarrow \mathrm{c}_{2}$, etc.) result in a widespectral-range optical absorption with characterized absorption bands. From the typical absorption spectra of CNTs in Fig. 13(b), it is seen that the characterized absorption bands in the NIR region are due to the transitions between the first and the second van Hove singularities. ${ }^{95}$ Fig. 13(c) shows the gap energies as a function of diameter, well-known as a Kataura plot. ${ }^{20,96}$ Each dot corresponds to a different pair of integers, hence a different type of nanotube. The shadowed region indicates the window of interest for optical communications, corresponding to the $1300-1600 \mathrm{~nm}$ range. This requires nanotubes with $0.8-1.3 \mathrm{~nm}$ diameters (as indicated by the solid lines in Fig. 13(c)) which are readily available.

The CNTs' one-dimensionality is the basis for their potential application as fast optical switches. ${ }^{97,98}$ Absorption at a given 


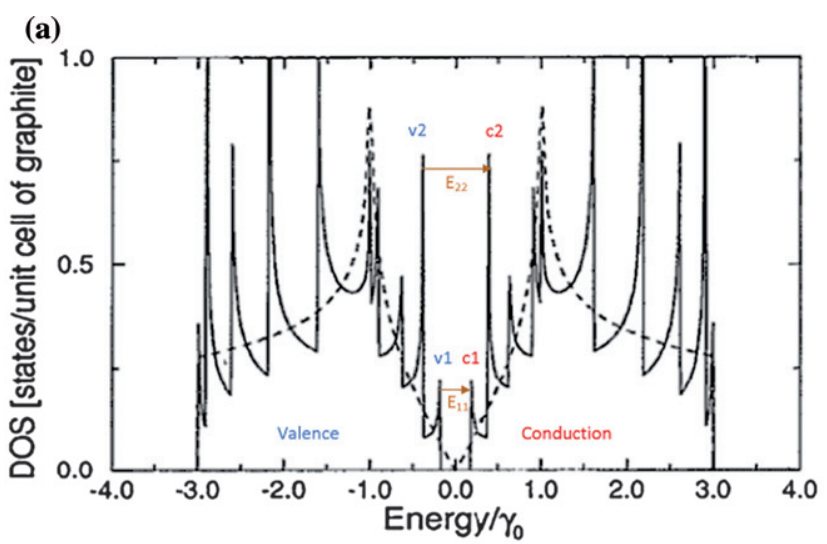

(b)

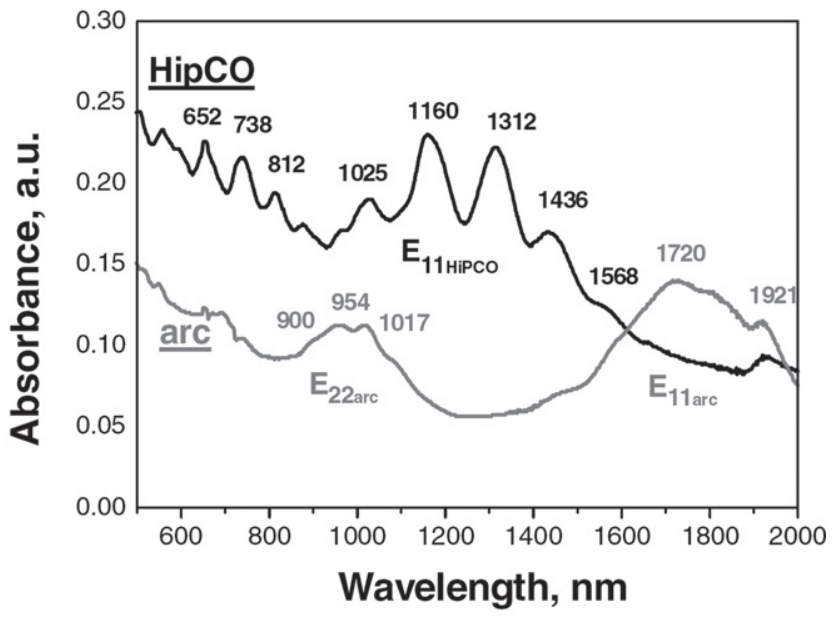

(c)

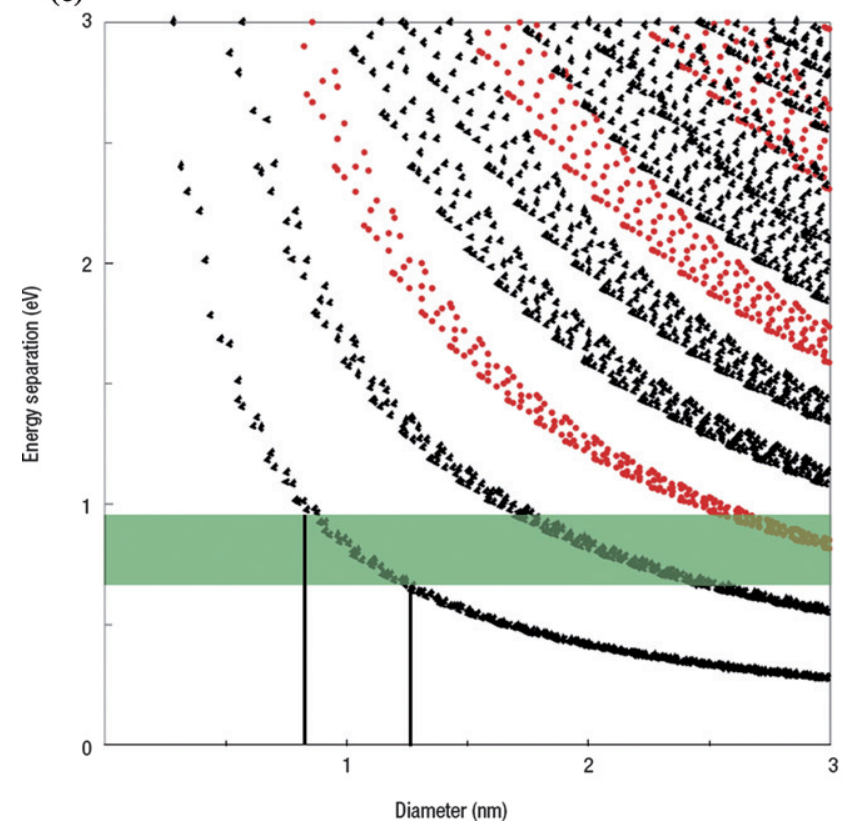

Fig. 13 (a) The electronic density of states for a $(10,0)$ zigzag semiconducting single-walled CNT. ${ }^{94}$ (b) Absorption spectra of two types of CNTs in polymer films. ${ }^{95} \mathrm{E}_{11}$ and $\mathrm{E}_{22}$ represent the electronic transitions between the first and the second van Hove singularities. (c) Kataura plot, the transition energies as a function of diameter of semiconducting (black) and metallic (red) nanotubes. http://www.photon.t.u-tokyo.ac.jp/ $\sim$ maruyama/kataura/kataura.html. wavelength creates electron-hole pairs. This causes band filling and the absorption saturates. A further power increase results in a reduced overall absorption or a bleaching of the sample. CNTs have indeed been reported to be nonlinear absorbers and show high third-order nonlinear polarizability $\left(\chi^{(3)} \approx 10^{-7}-10^{-10}\right.$ esu). ${ }^{19,45,97-99}$ An important physical property for ultrafast devices is the excited carriers' relaxation speed. A fast decay of the excited electron-hole pairs allows the system to go back into the linear absorption range, and a new saturation-relaxation cycle can begin. The CNT recovery time is inherently very fast and depends strongly on whether the absorption is to the first or second electronic sub-band. The relaxation from the second subband is much faster ( $40 \mathrm{fs}$ ) than from the first ( $10 \mathrm{ps})$. Nanotube bundles, with the naturally occurring semiconducting/metallic ratio $2: 1,{ }^{94}$ show even faster dynamics (sub-ps), due to the tunnelling of carriers from semiconducting to metallic tubes. Thus, while many key applications of CNTs in electronics require individual tubes with a given chirality for optimum performance, the uncontrolled chirality typical of CNTs is turning one of the major disadvantages of CNT technology into one of the key elements for the passively mode-locked lasers. ${ }^{100}$

\subsection{Mode-locked lasers}

In 2003, Set et al. demonstrated for the first time the saturable absorption property of single-walled CNTs for 1 ps ultra-short
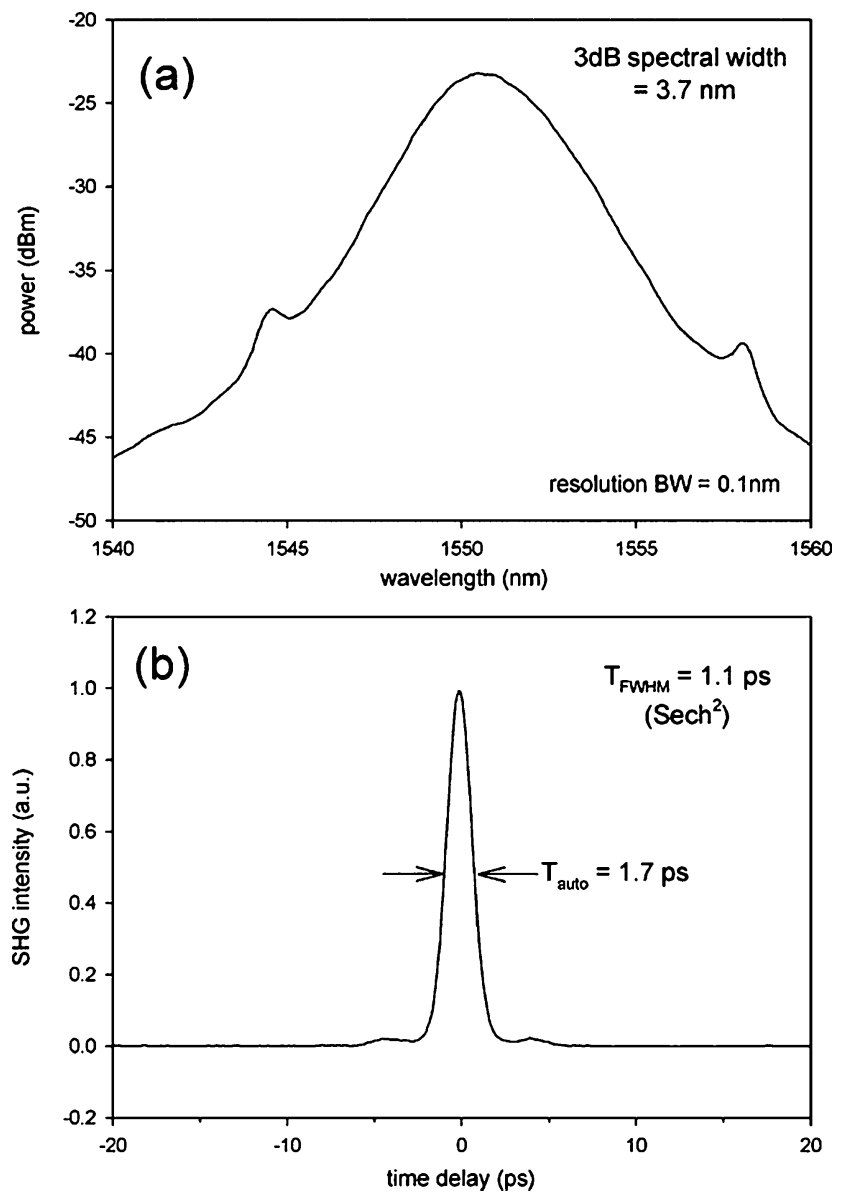

Fig. 14 Typical spectrum (a) and SHG autocorrelation trace (b) from a mode-locked fiber ring laser using SAINT ${ }^{88}$ 


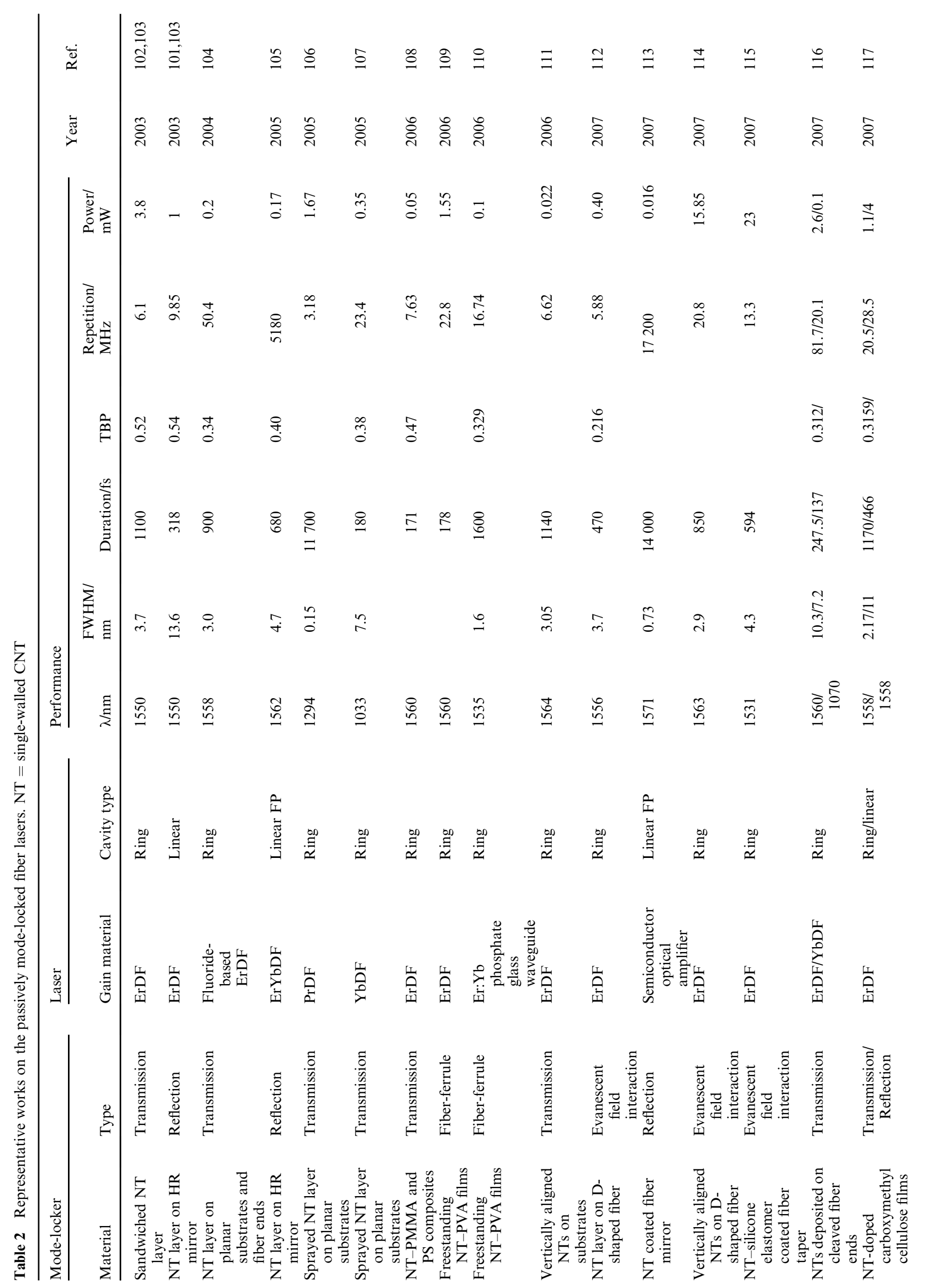




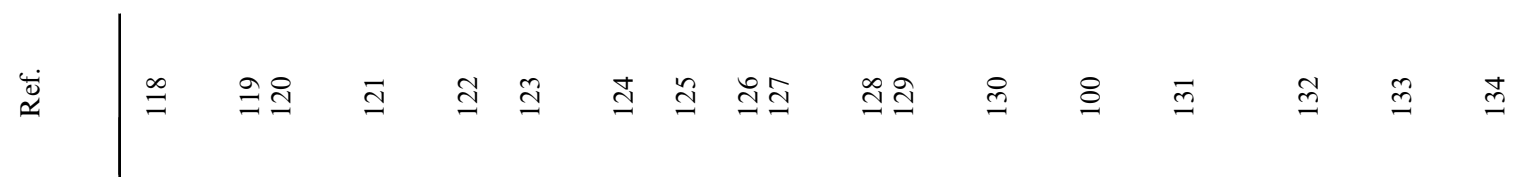

䒕

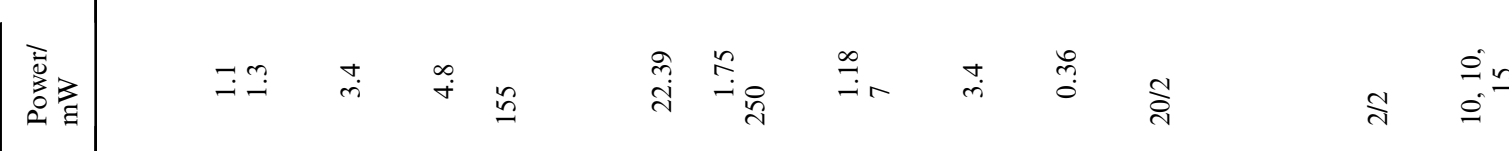

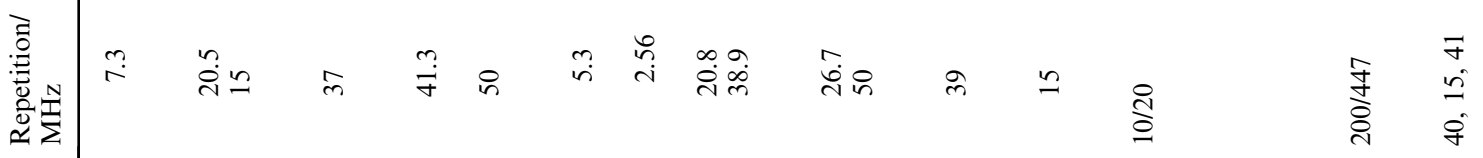

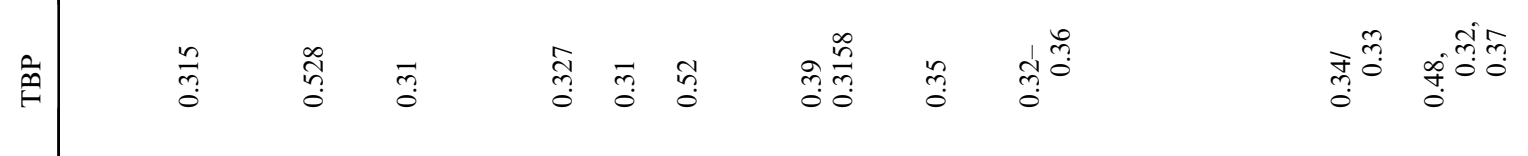

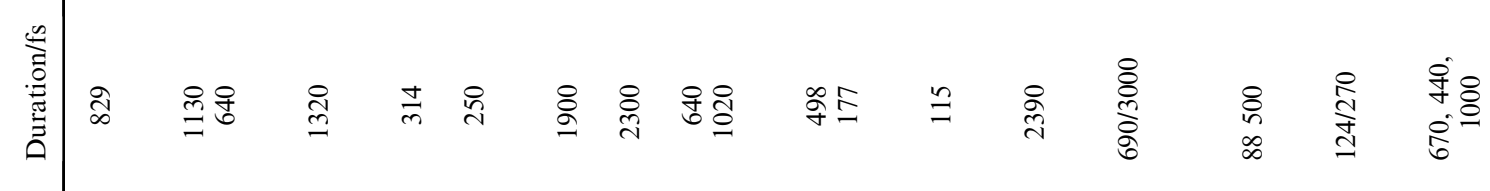

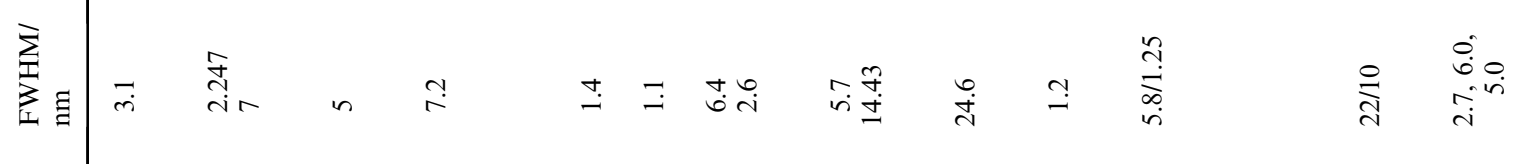

:

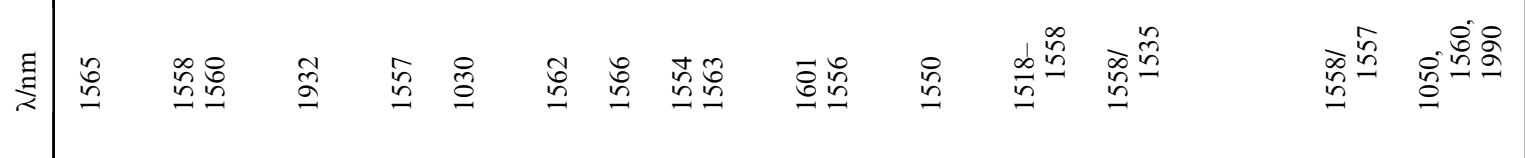

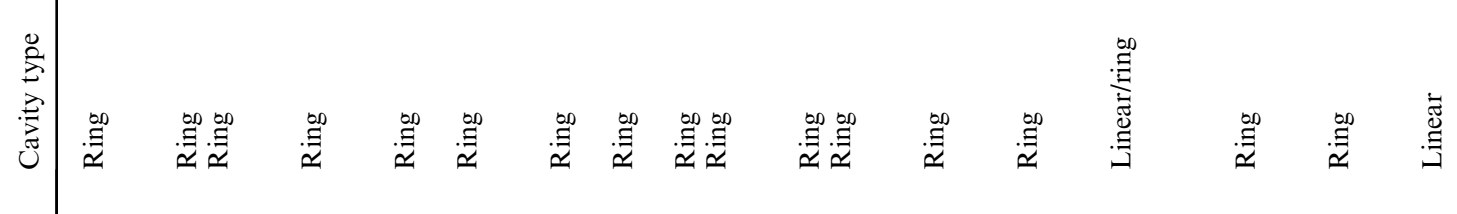

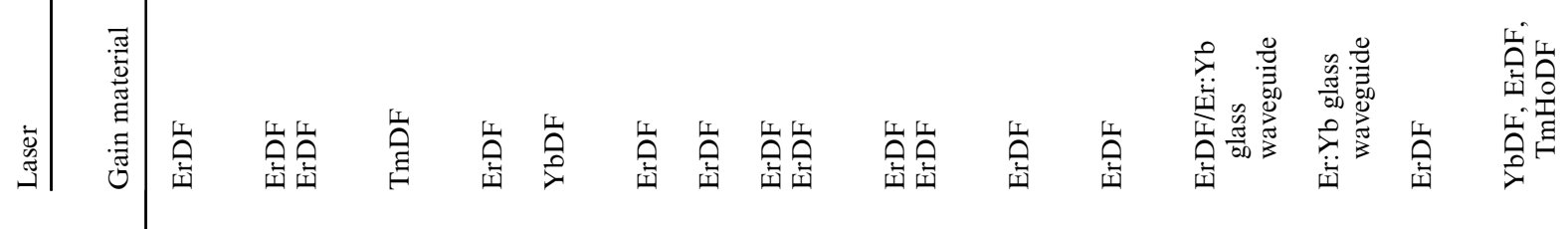

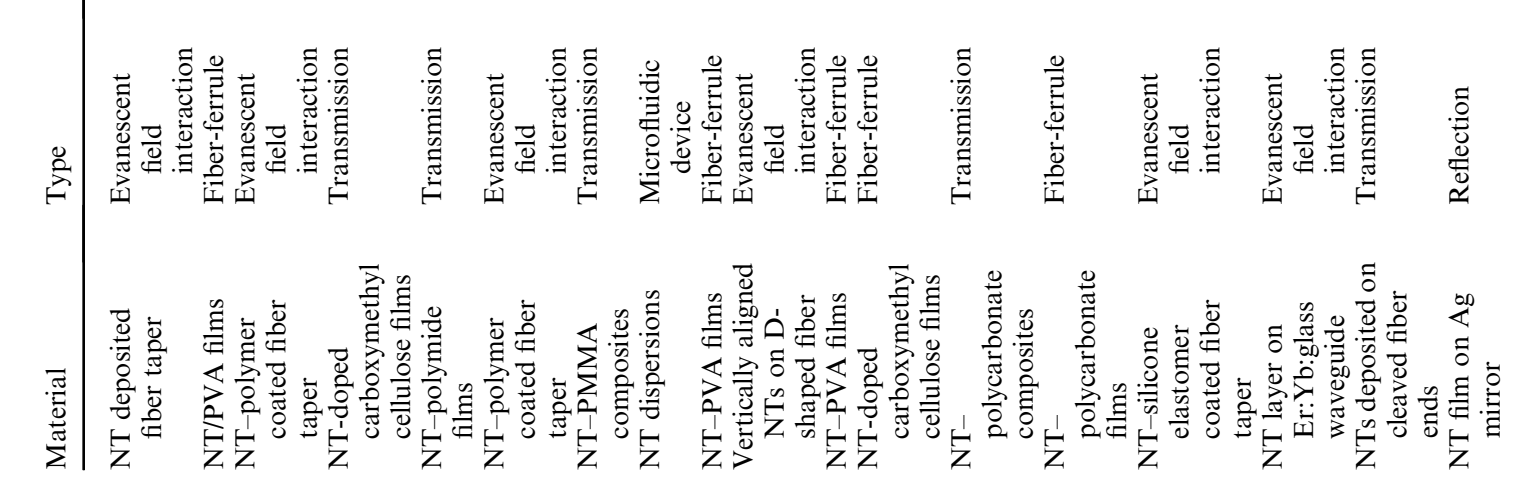


pulses at $1550 \mathrm{~nm} .{ }^{23}$ As shown in Fig. 1(b), the sprayed nanotube film on a quartz substrate can effectively suppress the low intensity background noise while allowing high-pass for the high intensity signal, resulting in fast mode-locking. Subsequently, employing such simple structures as saturable absorber, Set et al. successfully demonstrated the mode-locking from the erbiumdoped fiber (ErDF) lasers. ${ }^{101-103}$ As a result, 1.1 ps and $318 \mathrm{fs}$ pulse trains were obtained from the fiber lasers with ring and linear resonant cavity configurations, respectively. The typical output spectrum and SHG autocorrelation trace of soliton pulses from the mode-locked fiber ring laser are shown in Fig. 14. Since then, the CNT-based saturable absorbers are widely used as mode-locking elements for ultra-short pulse fiber lasers and solid state lasers. Tables 2 and 3 summarize respectively most of the representative works on the passively mode-locked fiber lasers and solid state lasers using nanotube saturable absorbers. The materials and structures of the mode-lockers, the gain medium and cavity of lasers, and the main parameters of the output pulses are given in the tables. Although various structures of the saturable absorbers have been designed (see Fig. 15 and 16) in recent few years, we generally name in this paper the CNT-based saturable absorbers as Saturable Absorbers Incorporating NanoTube, SAINTs for short, after Set et al. ${ }^{\mathbf{8}}$

Whereas the fabrication procedure of SESAMs is complex, costly and environmentally unfriendly (see Fig. 16(c)), the SAINT devices only need a low-cost room-temperature fabrication process. The linear and nonlinear parameters of SAINTs, e.g. linear transmission, absorption band and threshold power, etc., can be easily engineered by selecting the CNTs with the appropriate diameter range and by changing the thickness and concentration of the CNT or CNT-polymer layer. As a reflective device, SESAM can only work for lasers with a linear cavity and has a low damage threshold. In contrast, CNT and nanotubepolymer composites have a higher damage threshold and the flexibility of the nanotube composites allows the design and fabrication of different SAINT structures to fit the different requirements. To date, SAINTs have been successfully adopted in mode-locked fiber lasers and solid state lasers in both ring and linear configurations.

The typical structures of SAINTs are depicted in Fig. 15. Reflective and transmission type SAINTs were first employed for mode-locked fiber lasers in linear and ring cavities, respectively. ${ }^{\mathbf{8}}$ As shown in Fig. 16(a), the reflective type can be fabricated by directly spraying CNTs or coating nanotube-polymer solutions on high-reflection (HR) mirror. Fig. 17(b) illustrates a typical experimental setup of a mode-locked linear cavity fiber laser using reflective type SAINT. The gain medium, ErDF, is backward pumped by a $980 \mathrm{~nm}$ laser diode (LD). The output beam from one end of the ErDF is collimated and focused on the SAINT. After modulation, the beam is coupled back to the ErDF, resulting in the lasing oscillation. The Faraday mirror at the other end of the cavity is employed to compensate for birefringence in the resonator. $20 \%$ of the total power is coupled out as output and $80 \%$ remains in the cavity due to the fiber coupler. By shortening the cavity length in the linear configuration, one can obtain ultrashort pulse train with high repetition rate up to $17.2 \mathrm{GHz} .{ }^{113}$

The transmission type is composed of a sandwiched nanotube layer with transparent substrates, nanotube or nanotube-polymer films on glass or quartz substrate, free-standing 


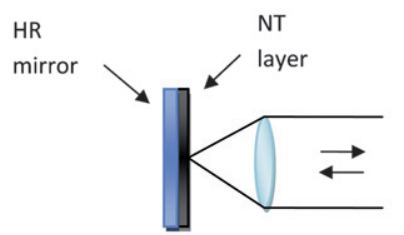

(a)

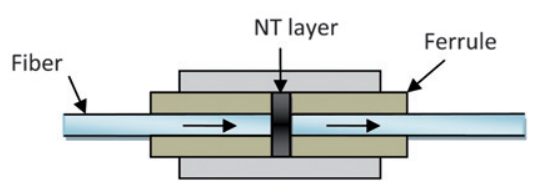

(c)

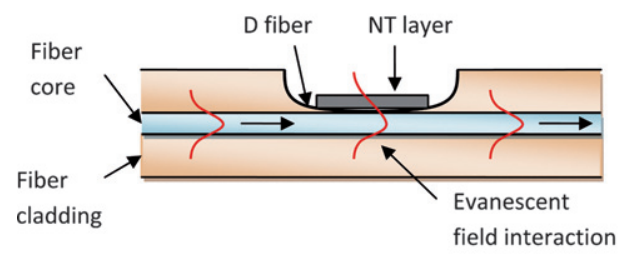

(e)

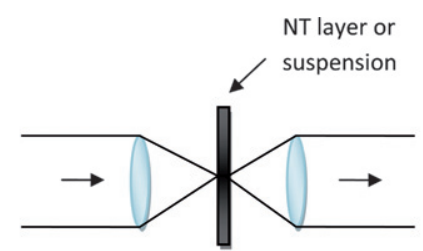

(b)

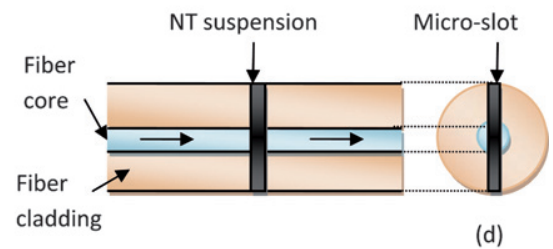

(d)

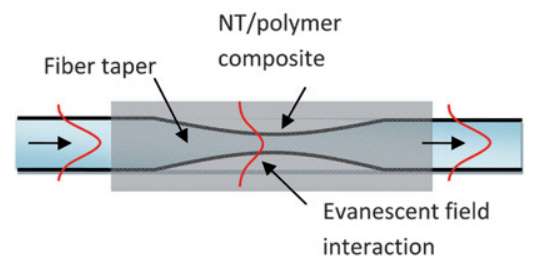

(f)

Fig. 15 Various types of SAINT: (a) reflective type, (b) transmission type, (c) fiber ferrule type, (d) microfluidic channel type, (e) D-shaped fiber type and (f) fiber taper type.

nanotube-polymer films and CNT suspensions. For the fiber ring lasers, the use of a transmission type SAINT would increase the difficulty in the cavity alignment as well as the loss of coupling. Instead, the fiber ferrule type can largely overcome such disadvantages and make the fiber laser system robust and easy to maintain. A typical mode-locked ring fiber laser using a ferrule type SAINT is illustrated in Fig. 17(a). The ErDF amplifier system is the same as that in Fig. 17(b). Two optical isolators are employed to avoid back reflection and guarantee laser quality. The intracavity filter is used to tune the output wavelength. With this laser system, Wang et al. realized continuously tunable output from $1518 \mathrm{~nm}$ to $1558 \mathrm{~nm}$ with $2.4 \mathrm{ps}$ pulse. ${ }^{100}$ The cavity structure of the ring laser using transmission type SAINT is quite similar to Fig. 17(a). Instead of the compact fiber ferrule, one has to utilize two sets of lenses and collimators to ensure the alignment and to minimize the coupling loss. It should be mentioned that the ferrule type SAINT merely requires the free-standing CNT-polymer films, as shown in Fig. 16(b), which is an essential advantage aimed towards industrially applicable SAINT devices. Their incorporation of CNTs into polymeric materials makes these the ideal choice as a photonic device integration platform. They are easily manipulated by methods such as embossing, stamping, sawing, wet or dry etching. They have a low-cost room-temperature fabrication process. Polymers can be synthesized with customer defined optical characteristics such as selective transparency bands in different spectral ranges, variable refractive indexes, low birefringence, etc.

To construct compact SAINTs, Nicholson et al. directly deposited single-walled nanotubes onto cleaved optical fiber end faces and fiber connectors using the optically driven deposition technique. ${ }^{116}$ Using this highly integrated SAINT, the authors demonstrated mode-locked ErDF laser with 247.5 fs pulses at $1560 \mathrm{~nm}$ and ytterbium-doped fiber (YbDF) laser with $137 \mathrm{fs}$ pulses at $1070 \mathrm{~nm}$. Separately, a novel SAINT based on a microfluidic channel fabricated in an optical fiber using fs laser micro-process technique was proposed by Martinez et al. ${ }^{125}$ As shown in Fig. 15(d), the SAINT is made by filling the CNT suspension into the microchannel, resulting in a more compact mode-locker. Incorporating the microchannel SAINT into an ErDF ring laser, the authors successfully observed 2.3 ps soliton pulse output with a $2.56 \mathrm{MHz}$ repetition rate.

Exploring new SAINT device, Song et al. designed a D-shaped fiber mode locker. ${ }^{12,114,127}$ As shown in Fig. 15(e), the modelocking is achieved by the interaction of the evanescent field of the waveguide mode with the CNT layer deposited in the D-shaped fiber. Compared with the other types of SAINT, this mode-locker possesses a long contact length between the propagation signal and the CNT layer, resulting in sufficient NLO interaction. As a result of effective mode-locking, a $470 \mathrm{fs}$ pulse train was achieved from an ErDF ring laser with a $5.88 \mathrm{MHz}$ repetition rate. ${ }^{112}$ In order to further improve the interaction efficiency, Song et al. replaced the randomly sprayed nanotube layer with a vertically aligned nanotube film for the D-shaped fiber mode locker. ${ }^{114}$ Using this well-defined SAINT, Song et al. realized 1.02 ps pulses with an average output power as high as $250 \mathrm{~mW}$, which is the highest output power reported so far for passively mode-locked fiber lasers using SAINT. ${ }^{127}$ The whole laser system can work for over 200 hours without a significant decrease in the output power, implying the excellent stability and reliability of the SAINT device. In the same vein, a fiber taper wrapped with the CNT-polymer composite was employed as a mode-locking component for fiber ring lasers. ${ }^{115,118,123}$ As shown in Fig. 15(f), polarization insensitive mode-locking can be 

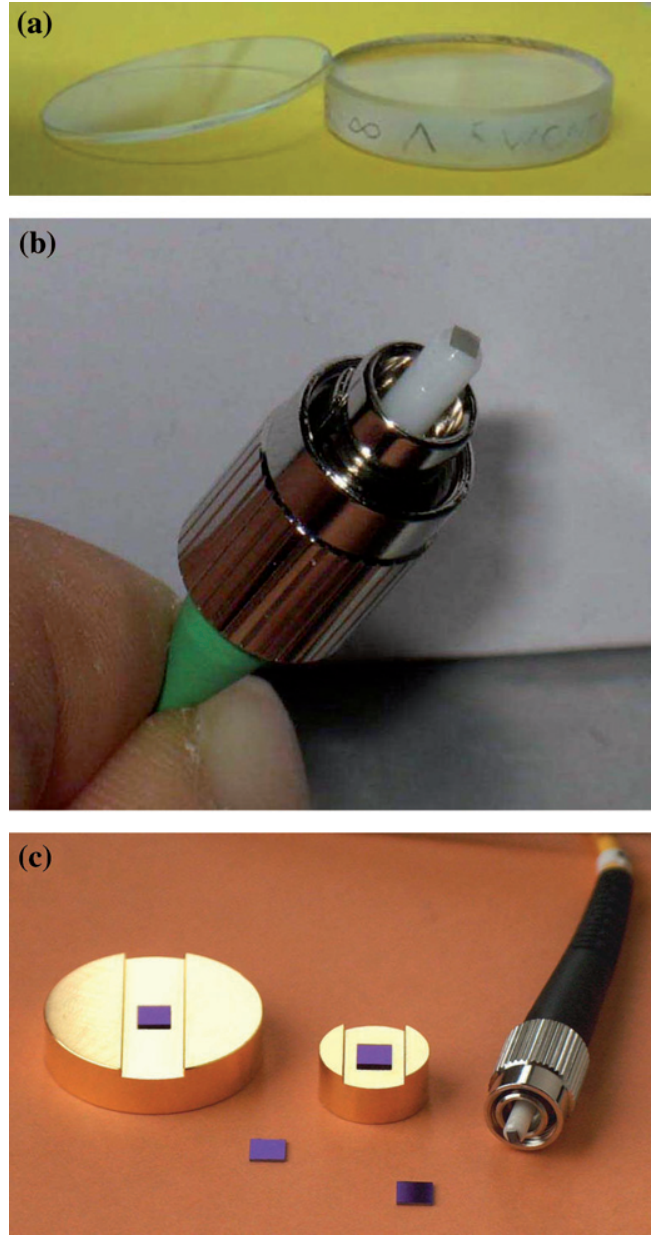

Fig. 16 Photographs of (a) transmission and reflective type SAINTs ${ }^{143}$ and (b) SAINT device made from CNT/polymer composite, ${ }^{122}$ compared with (c) commercially available SESAM products from BATOP GmbH, Germany. http://www.batop.de.

demonstrated by the evanescent field interaction with the nanotube-polymer coating when the guided light passes through the fiber taper. Using the fiber taper as mode-locker, Song et al. demonstrated 829 fs soliton pulses in an ErDF ring laser with a $7.3 \mathrm{MHz}$ repetition rate. ${ }^{118} \mathrm{Kieu}$ and Mansuripur observed 594 fs pulses at $1531 \mathrm{~nm}$ from an ErDF ring laser ${ }^{115}$ and $250 \mathrm{fs}$ pulses at $1030 \mathrm{~nm}$ from a YbDF ring laser with an average output power as high as $155 \mathrm{~mW} .^{123}$

In addition to the mode-locked fiber lasers, the transmission and reflective type SAINTs were employed for the mode-locked solid state lasers. Il'ichev et al. applied single-walled CNT suspensions in heavy water as a mode-locking component for a range of solid state lasers: Er:glass, ${ }^{135}$ colour center $\mathrm{F}_{2}-\mathrm{LiF},{ }^{136}$ YAP:Nd, YAG:Nd and Nd:glass lasers. ${ }^{138}$ Mode-locked ps pulses were demonstrated in these lasers with broad output wavelengths from $1540 \mathrm{~nm}$ to $1340 \mathrm{~nm}$, then to $1055 \mathrm{~nm}$. Schibli et al. successfully demonstrated self-starting mode-locking for $\mathrm{Nd}$ :glass and $\mathrm{Er} / \mathrm{Yb}$ :glass lasers using a reflective type SAINT. ${ }^{137}$ The experimental setup is illustrated in Fig. 18 (a). The modelocker was fabricated by spin-coating a nanotube-polymer (polymide and carboxymethyl cellulose) composite onto a $\mathrm{TiO}_{2} /$ $\mathrm{SiO}_{2}$ dielectric mirror. The Er: $\mathrm{Yb}$ glass laser can produce ultra-

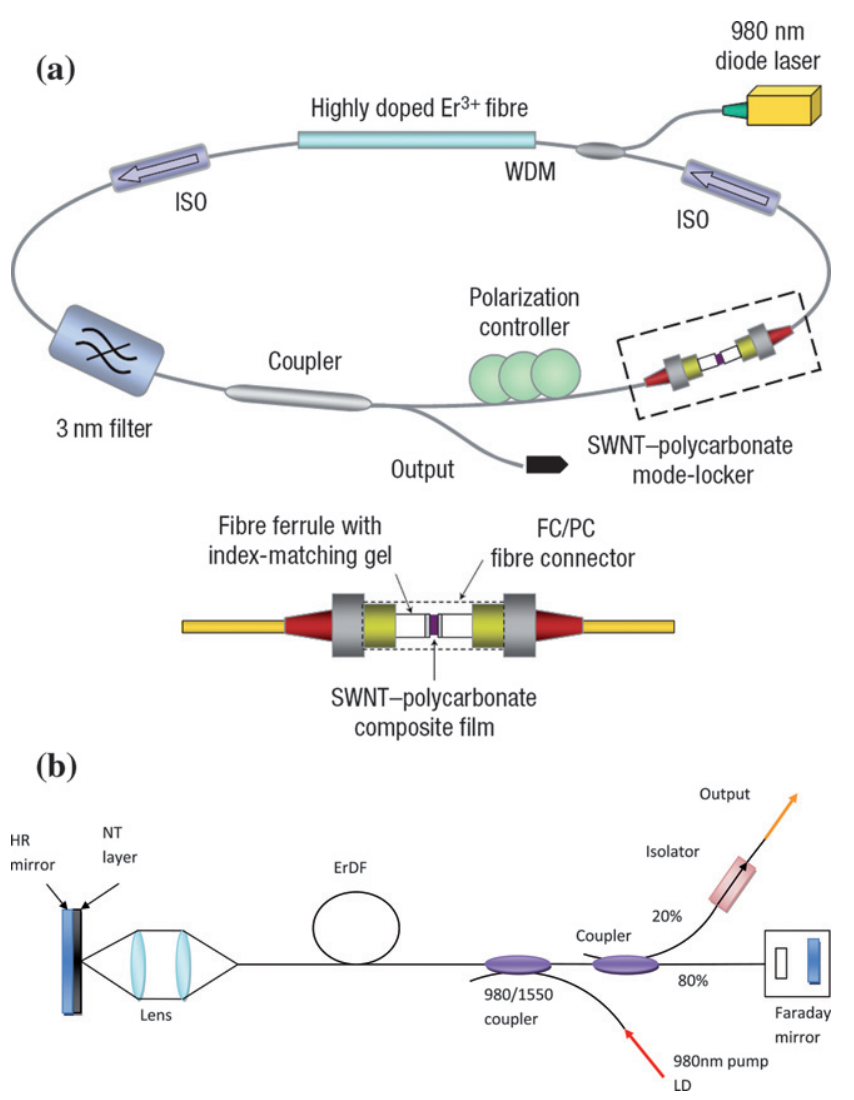

Fig. 17 Schematic diagrams of the mode-locked fiber lasers in (a) ring ${ }^{\mathbf{1 0 0}}$ and (b) linear ${ }^{88}$ cavity configurations.
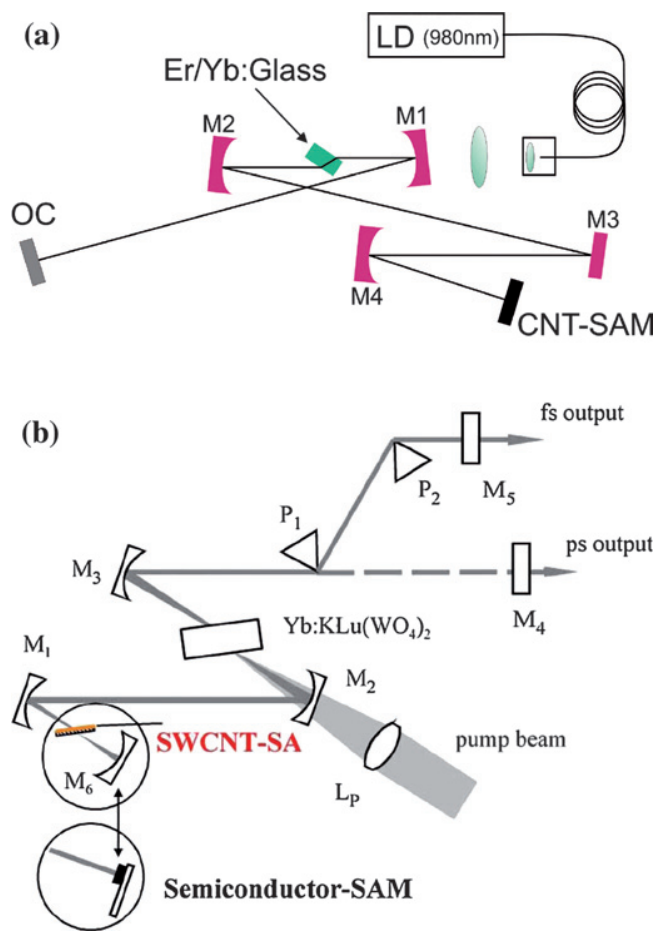

Fig. 18 Schematic diagrams of the mode-locked solid state lasers using (a) reflective type ${ }^{137}$ and (b) transmission type ${ }^{141}$ SAINTs. 

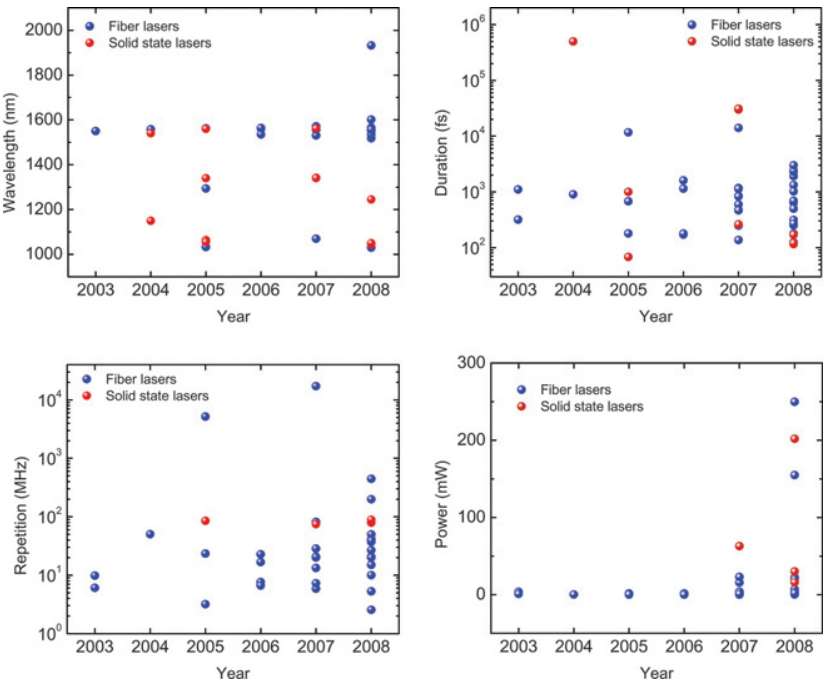

Fig. 19 Annual improvement of output performances of the modelocked fiber lasers and solid state lasers using SAINTs.

short pulses, as fast as $68 \mathrm{fs}$, at $1560 \mathrm{~nm}$. A hybrid saturable absorber was fabricated by Fong et al. by depositing a CNT layer onto a semiconductor AlAs/GaAs distributed Bragg reflector mirror. ${ }^{139}$ With this saturable absorber, the authors obtained $63 \mathrm{~mW} 261 \mathrm{fs}$ soliton pulses from a mode-locked Er:Yb glass laser. Several groups reported a low-cost SAINT device fabricated by coating a CNT-PMMA composite on transparent substrates. ${ }^{141-143}$ The CNT-PMMA-based saturable absorbers were applied to a range of solid state lasers, i.e. Cr:forsterite ${ }^{\mathbf{1 4 2}}$ and $\mathrm{Yb}: \mathrm{KLu}\left(\mathrm{WO}_{4}\right)_{2}$ lasers. ${ }^{141,143}$ Fig. 18(b) depicts the experimental setup for the mode-locked $\mathrm{Yb}: \mathrm{KLu}\left(\mathrm{WO}_{4}\right)_{2}$ laser using transmission type SAINT. The generation of less than $200 \mathrm{fs}$ pulses from the above lasers indicates the effective mode-locking by the SAINTs.

\subsection{Discussion}

Based on the data in Tables 2 and 3, statistics for the annual trace of output performances of the mode-locked fiber lasers and solid state lasers using SAINTs are given in Fig. 19. It is noted that (1) the output wavelength of the mode-locked lasers has covered from $1.0 \mu \mathrm{m}$ to $2.0 \mu \mathrm{m}$ by using different gain materials; (2) the pulse duration can be compressed to $<100 \mathrm{fs}$ and be tuned from ps to fs; (3) the repetition rate can be controlled from $\mathrm{MHz}$ to $\mathrm{GHz}$; and (4) the average output power has become larger than $200 \mathrm{~mW}$. Meanwhile, an effort to develop new CNT modelockers for different types of lasers, i.e. waveguide lasers, ${ }^{132}$ is still in progress. These remarkable achievements indicate the validity and potential commercial value of SAINTs for passively modelocked lasers. Using SAINTs, ultra-short mode-locked fiber and solid state lasers with different output parameters would match the various requirements for real life applications in fiber communications, surgery, etc. ${ }^{89}$

It should be mentioned that single-walled CNTs can be used as mode-locking element due to the large absorption cross section in NIR, low saturation intensity and ultra-short exciton decay time. Multi-walled CNTs are usually composed of both metallic and semiconducting CNTs, resulting in a metal like property.
Recently, a few groups found the pristine multi-walled CNTs, nitrogen-doped nanotubes ${ }^{144}$ and $\mathrm{ZnO}$-beaded nanotubes ${ }^{145,146}$ exhibit clear saturation absorption and ultra-fast exciton decay, which could be used for nonlinear optical switching and modelocking. However, compared with the low saturation intensity of single-walled nanotubes ( $\sim$ tens of $\mathrm{MW} / \mathrm{cm}^{2}$ ), the multi-walled nanotubes require a much higher irradiation intensity ( $\sim$ tens of $\mathrm{GW} / \mathrm{cm}^{2}$ ) in order to saturate. In addition to CNTs, a number of nanomaterials, e.g. $\mathrm{PbS}$ quantum dots, ${ }^{147,148} \mathrm{AgInSe}_{2}$ nanorods $^{149}$ and Nano-Ag:polymer composite ${ }^{150}$ have also been investigated as nanophotonic components for mode-locking or optical switching.

\section{Prospects}

Information exchange and communication is at the very core of our global society. Photonics provides the infrastructural hardware and technological backbone. The global demand for photonic infrastructure continues to increase by a stunning $40 \%$ p.a., while customers are obviously not prepared to pay a corresponding increase in costs. Thus, the need, in optical networking alone, for photonic components that meet the performance criteria as well as the economic requirements opens the door to novel technologies capable of high-yield, low-cost and potentially environmentally friendly manufacturing, while delivering high performance and enabling unique functions. With the excellent properties and decreasing price, CNTs and CNT composites are suitable candidates to satisfy the requirements for the next generation of photonic components. Essentially the potential applications of CNTs and CNT composites extends far beyond optical switches, optical limiters and mode-lockers, i.e. to flexible transparent conductors, charge transport layers in light emitting diodes and photovoltaic cells. The CNTs and CNT composites will therefore find a wide range of applications, not only in optical communications and integrated optical networks, but also in biomedical instruments, chemical analysis, timeresolved spectroscopy, environmental sensing, microscopy and surgery.

\section{Acknowledgements}

This work was supported by the Science Foundation Ireland (SFI) under Grant No. 08/CE/I1432. J.W. thanks SFI for his postdoctoral research fellowship. Y.C. thanks National Natural Science Foundation of China (20876046), Key project of Ministry of Education of China (309013), Shanghai Municipal Educational Commission for the Shuguang fellowship (08GG10) and Shanghai Eastern Scholarship for the financial support.

\section{References}

1 R. W. Boyd, Nonlinear Optics, Academic press, 2002.

2 Molecular Nonlinear Optics - Materials, Physics and Devices, ed. J. Zyss, Elsevier Publishers, 1993.

3 P. N. Prasad and D. J. Williams, Introduction to Nonlinear Optical Effects in Molecules and Polymers, Wiley-Interscience, 1991.

4 P. N. Prasad, Nanophotonics, WileyBlackwell, 2004.

5 K. Mansour, M. J. Soileau and E. W. Van Stryland, J. Opt. Soc. Am. $B, 1992,9,1100-1109$.

6 K. M. Nashold and D. P. Walter, J. Opt. Soc. Am. B, 1995, 12, 12281237. 
7 W. J. Blau, H. J. Byrne, D. J. Cardin, T. J. Dennis, J. P. Hare, H. W. Kroto, R. Taylor and D. R. M. Walton, Phys. Rev. Lett., 1991, 67, 1423-1425.

8 L. W. Tutt and A. Kost, Nature, 1992, 356, 225-226.

9 P. Chen, X. Wu, X. Sun, J. Lin, W. Ji and K. L. Tan, Phys. Rev. Lett., 1999, 82, 2548-2551.

10 L. Vivien, P. Lancon, D. Riehl, F. Hache and E. Anglaret, Carbon, 2002, 40, 1789-1797.

11 Y. Chen, Y. Lin, Y. Liu, J. Doyle, N. He, X. D. Zhuang, J. R. Bai and W. J. Blau, J. Nanosci. Nanotechnol., 2007, 7, 1268-1283.

12 J. Wang and W. J. Blau, J. Opt. A: Pure Appl. Opt., 2009, 11, 024001.

13 A. K. Geim and K. S. Novoselov, Nat. Mater., 2007, 6, 183-191.

14 J. Wang, Y. Hernandez, M. Lotya, J. N. Coleman and W. J. Blau, Adv. Mater., 2009, 21, 2430-2435.

15 P. M. Ajayan, Chem. Rev., 1999, 99, 1787-1799.

16 R. H. Baughman, A. A. Zakhidov and W. A. de Heer, Science, 2002, 297, 787-792.

17 P. Avouris, Z. H. Chen and V. Perebeinos, Nat. Nanotechnol., 2007, 2, 605-615.

18 P. Avouris, M. Freitag and V. Perebeinos, Nat. Photonics, 2008, 2, 341-350.

19 V. A. Margulis and T. A. Sizikova, Phys. B, 1998, 245, 173-189.

20 R. Saito, G. Dresselhaus and M. S. Dresselhaus, Phys. Rev. B: Condens. Matter Mater. Phys., 2000, 61, 2981-2990.

21 A. M. Nemilentsau, G. Y. Slepyan, A. A. Khrutchinskii and S. A. Maksimenko, Carbon, 2006, 44, 2246-2253.

22 J. Wang and W. J. Blau, Appl. Phys. B: Lasers Opt., 2008, 91, 521-524.

23 S. Y. Set, H. Yaguchi, M. Jablonski, Y. Tanaka, Y. Sakakibara, A. Rozhin, M. Tokumoto, H. Kataura, Y. Achiba and K. Kikuchi, in Proc. Optical Fiber Communication Conf.'03, Atlanta, GA, 2003, p. FL2.

24 M. Sheik-Bahae, A. A. Said, T. H. Wei, D. J. Hagan and E. W. Vanstryland, IEEE J. Quantum Electron., 1990, 26, 760-769.

25 J. Wang and W. J. Blau, SPIE Newsroom, 2007, DOI: 10.1117/ 2.1200711.0916.

26 F. Henari, J. Callaghan, H. Stiel, W. Blau and D. J. Cardin, Chem. Phys. Lett., 1992, 199, 144-148.

27 J. W. Perry, K. Mansour, I. Y. S. Lee, X. L. Wu, P. V. Bedworth, C. T. Chen, D. Ng, S. R. Marder, P. Miles, T. Wada, M. Tian and H. Sasabe, Science, 1996, 273, 1533-1536.

28 S. M. O'Flaherty, S. V. Hold, M. J. Cook, T. Torres, Y. Chen, M. Hanack and W. J. Blau, Adv. Mater., 2003, 15, 19-32.

29 J. J. Doyle, J. Wang, S. M. O'Flaherty, Y. Chen, A. Slodek, T. Hegarty, L. Carpenter II, D. Wöhrle, M. Hanack and W. J. Blau, J. Opt. A: Pure Appl. Opt., 2008, 10, 075101.

30 Y. Chen, L. Gao, M. Feng, L. L. Gu, N. He, J. Wang, Y. Araki, W. J. Blau and O. Ito, Mini-Rev. Org. Chem., 2009, 6, 55-65.

31 W. Blau, H. Byrne, W. M. Dennis and J. M. Kelly, Opt. Commun., 1985, 56, 25-29.

32 M. O. Senge, M. Fazekas, E. G. A. Notaras, W. J. Blau, M. Zawadzka, O. B. Locos and E. M. N. Mhuircheartaigh, $A d v$. Mater., 2007, 19, 2737-2774.

33 Y. P. Sun and J. E. Riggs, Int. Rev. Phys. Chem., 1999, 18, 43-90.

34 Y. P. Sun, J. E. Riggs, K. B. Henbest and R. B. Martin, J. Nonlinear Opt. Phys. Mater., 2000, 9, 481-503.

35 C. Zhang, Y. L. Song and X. Wang, Coord. Chem. Rev., 2007, 251, $111-141$.

36 L. W. Tutt and T. F. Boggess, Progress in Quantum Electronics, 1993, 17, 299-338.

37 G. S. He, L. S. Tan, Q. D. Zheng and P. N. Prasad, Chem. Rev., 2008, 108, 1245-1330.

38 X. Sun, R. Q. Yu, G. Q. Xu, T. S. A. Hor and W. Ji, Appl. Phys. Lett., 1998, 73, 3632-3634.

39 X. Sun, Y. N. Xiong, P. Chen, J. Y. Lin, W. Ji, J. H. Lim, S. S. Yang, D. J. Hagan and E. W. Van Stryland, Appl. Opt., 2000, 39, 19982001.

40 S. R. Mishra, H. S. Rawat, S. C. Mehendale, K. C. Rustagi, A. K. Sood, R. Bandyopadhyay, A. Govindaraj and C. N. R. Rao, Chem. Phys. Lett., 2000, 317, 510-514.

41 L. Vivien, D. Riehl, F. Hache and E. Anglaret, J. Nonlinear Opt. Phys. Mater., 2000, 9, 297-307.

42 L. Vivien, D. Riehl, E. Anglaret and F. Hache, IEEE J. Quantum Electron., 2000, 36, 680-686.

43 L. Vivien, J. Moreau, D. Riehl, P. A. Alloncle, M. Autric, F. Hache and E. Anglaret, J. Opt. Soc. Am. B, 2002, 19, 2665-2672.
44 L. Vivien, D. Riehl, J. F. Delouis, J. A. Delaire, F. Hache and E. Anglaret, J. Opt. Soc. Am. B, 2002, 19, 208-214.

45 S. M. O'Flaherty, S. V. Hold, M. E. Brennan, M. Cadek, A. Drury, J. N. Coleman and W. J. Blau, J. Opt. Soc. Am. B, 2003, 20, 49-58.

46 I. M. Belousova, N. G. Mironova and M. S. Yur'ev, Optics and Spectroscopy, 2003, 94, 86-91.

47 I. M. Belousova, N. G. Mironova, A. G. Scobelev and M. S. Yur'ev, Opt. Commun., 2004, 235, 445-452.

48 I. M. Belousova, V. P. Belousov, O. B. Danilov, N. G. Mironova, T. D. Murav'eva, V. V. Ryl'kov, A. G. Skobelev, M. S. Yur'ev and A. N. Ponomarev, J. Opt. Technol., 2004, 71, 130-135.

49 L. Vivien, E. Anglaret, D. Riehl, F. Hache, F. Bacou, M. Andrieux, F. Lafonta, C. Journet, C. Goze, M. Brunet and P. Bernier, Opt. Commun., 2000, 174, 271-275.

50 J. Wang and W. J. Blau, J. Phys. Chem. C, 2008, 112, 2298-2303.

51 N. Izard, P. Billaud, D. Riehl and E. Anglaret, Opt. Lett., 2005, 30, $1509-1511$.

52 J. E. Riggs, D. B. Walker, D. L. Carroll and Y. P. Sun, J. Phys. Chem. B, 2000, 104, 7071-7076.

53 Z. X. Jin, L. Huang, S. H. Goh, G. Q. Xu and W. Ji, Chem. Phys. Lett., 2002, 352, 328-333.

54 L. Vivien, D. Riehl, P. Lancon, F. Hache and E. Anglaret, Opt. Lett., 2001, 26, 223-225.

55 F. E. Hernandez, W. Shensky, I. Cohanoschi, D. J. Hagan and E. W. Van Stryland, Appl. Opt., 2002, 41, 1103-1107.

56 L. Vivien, E. Anglaret, D. Riehl, F. Bacou, C. Journet, C. Goze, M. Andrieux, M. Brunet, F. Lafonta, P. Bernier and F. Hache, Chem. Phys. Lett., 1999, 307, 317-319.

57 S. Giordani, S. D. Bergin, V. Nicolosi, S. Lebedkin, M. M. Kappes, W. J. Blau and J. N. Coleman, J. Phys. Chem. B, 2006, 110, 1570815718.

58 S. D. Bergin, V. Nicolosi, P. V. Streich, S. Giordani, Z. Y. Sun, A. H. Windle, P. Ryan, N. P. Niraj, Z. T. Wang, L. Carpenter, W. J. Blau, J. Boland, J. P. Hamilton and J. N. Coleman, $A d v$. Mater., 2008, 20, 1876-1881.

59 C. Nitschke, S. M. O'Flaherty, M. Kroll, J. J. Doyle and W. J. Blau, Chem. Phys. Lett., 2004, 383, 555-560.

60 J. J. Doyle, V. Nicolosi, S. M. O'Flaherty, D. Vengust, A. Drury, D. Mihailovic, J. N. Coleman and W. J. Blau, Chem. Phys. Lett., 2007, 435, 109-113.

61 J. Wang and W. J. Blau, Chem. Phys. Lett., 2008, 465, 265-271.

62 N. Izard, C. Menard, D. Riehl, E. Doris, C. Mioskowski and E. Anglaret, Chem. Phys. Lett., 2004, 391, 124-128.

63 S. Webster, M. Reyes-Reyes, X. Pedron, R. López-Sandoval, M. Terrones and D. L. Carroll, Adv. Mater., 2005, 17, 1239-1243.

64 E. M. Ni Mhuircheartaigh, S. Giordani and W. J. Blau, J. Phys. Chem. B, 2006, 110, 23136-23141.

65 B. Ballesteros, G. de la Torre, C. Ehli, G. M. Aminur Rahman, F. Agulló-Rueda, D. M. Guldi and T. Torres, J. Am. Chem. Soc., 2007, 129, 5061-5068.

66 R. Chitta, A. S. D. Sandanayaka, A. L. Schumacher, L. D’Souza, Y. Araki, O. Ito and F. D'Souza, J. Phys. Chem. C, 2007, 111, 6947-6955.

67 G. de la Torre, W. J. Blau and T. Torres, Nanotechnology, 2003, 14, $765-771$.

68 Z. B. Liu, J. G. Tian, Z. Guo, D. M. Ren, F. Du, J. Y. Zheng and Y. S. Chen, Adv. Mater., 2008, 20, 511-515.

69 N. He, Y. Chen, J. Bai, J. Wang, W. J. Blau and J. Zhu, J. Phys. Chem. C, 2009, 113, 13029-13035.

70 K. C. Chin, A. Gohel, H. I. Elim, W. Ji, G. L. Chong, K. Y. Lim, C. H. Sow and A. T. S. Wee, Chem. Phys. Lett., 2004, 383, 72-75.

71 K. C. Chin, A. Gohel, W. Z. Chen, H. I. Elim, W. Ji, G. L. Chong, C. H. Sow and A. T. S. Wee, Chem. Phys. Lett., 2005, 409, 85-88.

72 S. A. O'Flaherty, R. Murphy, S. V. Hold, M. Cadek, J. N. Coleman and W. J. Blau, J. Phys. Chem. B, 2003, 107, 958-964.

73 X. L. Xie, Y. W. Mai and X. P. Zhou, Mater. Sci. Eng., R, 2005, 49, 89-112.

74 Y. Lin, M. J. Meziani and P. Sun, J. Mater. Chem., 2007, 17, $1143-$ 1148.

75 B. I. Kharisov, O. V. Kharissova, H. L. Gutierrez and U. O. Mendez, Ind. Eng. Chem. Res., 2009, 48, 572-590.

76 S. A. Curran, P. M. Ajayan, W. J. Blau, D. L. Carroll, J. N. Coleman, A. B. Dalton, A. P. Davey, A. Drury, B. McCarthy, S. Maier and A. Strevens, Adv. Mater., 1998, 10, 1091. 
77 Z. X. Jin, X. Sun, G. Q. Xu, S. H. Goh and W. Ji, Chem. Phys. Lett., 2000, 318, 505-510.

78 L. Q. Liu, S. A. Zhang, T. J. Hu, Z. X. Guo, C. Ye, L. M. Dai and D. B. Zhu, Chem. Phys. Lett., 2002, 359, 191-195.

79 M. Xu, T. Zhang, B. Gu, J. L. Wu and Q. Chen, Macromolecules, 2006, 39, 3540-3545.

80 Z. Li, Y. Q. Dong, M. Haussler, J. W. Y. Lam, Y. P. Dong, L. J. Wu, K. S. Wong and B. Z. Tang, J. Phys. Chem. B, 2006, 110, 2302-2309.

81 H. X. Wu, X. Q. Qiu, W. M. Cao, Y. H. Lin, R. F. Cai and S. X. Qian, Carbon, 2007, 45, 2866-2872.

82 H. X. Wu, R. Tong, X. Q. Qiu, H. F. Yang, Y. H. Lin, R. F. Cai and S. X. Qian, Carbon, 2007, 45, 152-159.

83 Q. Wang, Y. J. Qin, Y. J. Zhu, X. Huang, Y. X. Tian, P. Zhang, Z. X. Guo and Y. L. Wang, Chem. Phys. Lett., 2008, 457, 159162 .

84 J. Wang, D Früchtl, Z. Sun, J. N. Coleman and W. J. Blau, 2009, to be submitted.

85 Y. Hernandez, V. Nicolosi, M. Lotya, F. M. Blighe, Z. Sun, S. De, I. T. McGovern, B. Holland, M. Byrne, Y. K. Gun'Ko, J. J. Boland, P. Niraj, G. Duesberg, S. Krishnamurthy, R. Goodhue, J. Hutchison, V. Scardaci, A. C. Ferrari and J. N. Coleman, Nat. Nanotechnol., 2008, 3, 563-568.

86 Y. Xu, Z. Liu, X. Zhang, Y. Wang, J. Tian, Y. Huang, Y. Ma, X. Zhang and Y. Chen, Adv. Mater., 2009, 21, 1275-1279.

87 Z. B. Liu, Y. Wang, X. L. Zhang, Y. F. Xu, Y. S. Chen and J. G. Tian, Appl. Phys. Lett., $2009,94$.

88 S. Y. Set, H. Yaguchi, Y. Tanaka and M. Jablonski, IEEE J. Sel. Top. Quantum Electron., 2004, 10, 137-146.

89 W. J. Blau and J. Wang, Nat. Nanotechnol., 2008, 3, 705-706.

90 E. P. Ippen, Appl. Phys. B: Lasers Opt., 1994, 58, 159-170.

91 H. A. Haus, IEEE J. Sel. Top. Quantum Electron., 2000, 6, 11731185.

92 M. E. Fermann and I. Hartl, IEEE J. Sel. Top. Quantum Electron., 2009, 15, 191-206.

93 U. Keller, K. J. Weingarten, F. X. Kartner, D. Kopf, B. Braun, I. D. Jung, R. Fluck, C. Honninger, N. Matuschek and J. A. derAu, IEEE J. Sel. Top. Quantum Electron., 1996, 2, 435-453.

94 R. Saito, M. Fujita, G. Dresselhaus and M. S. Dresselhaus, Appl. Phys. Lett., 1992, 60, 2204-2206.

95 A. I. Chernov, E. D. Obraztsova and A. S. Lobach, Phys. Status Solidi B, 2007, 244, 4231-4235.

96 H. Kataura, Y. Kumazawa, Y. Maniwa, I. Umezu, S. Suzuki, Y. Ohtsuka and Y. Achiba, Synth. Met., 1999, 103, 2555-2558.

97 Y. C. Chen, N. R. Raravikar, L. S. Schadler, P. M. Ajayan, Y. P. Zhao, T. M. Lu, G. C. Wang and X. C. Zhang, Appl. Phys. Lett., 2002, 81, 975-977.

98 S. Tatsuura, M. Furuki, Y. Sato, I. Iwasa, M. Q. Tian and H. Mitsu, Adv. Mater., 2003, 15, 534-537.

99 S. Curran, A. P. Davey, J. Coleman, A. Dalton, B. McCarthy, S. Maier, A. Drury, D. Gray, M. Brennan, K. Ryder, M. Lamy de la Chapelle, C. Joumet, P. Bemier, H. J. Byme, D. Carroll, P. M. Ajayan, S. J. Lefran and W. J. Blau, Synth. Met., 1999, 103, $2559-2562$.

100 F. Wang, A. G. Rozhin, V. Scardaci, Z. Sun, F. Hennrich, I. H. White, W. I. Milne and A. C. Ferrari, Nat. Nanotechnol., 2008, 3, 738-742.

101 S. Y. Set, H. Yaguchi, Y. Tanaka, M. Jablonski, Y. Sakakibara, A. Rozhin, M. Tokumoto, H. Kataura, Y. Achiba and K. Kikuchi, in Proc. Optical Fiber Communication Conf.'03, Atlanta, GA, 2003, p. PD44.

102 S. Y. Set, H. Yaguchi, Y. Tanaka, M. Jablonski, Y. Sakakibara, M. Tokumoto, H. Kataura, Y. Achiba, K. Kikuchi and S. Yamashita, in Proc. CLEO'03, Baltimore, MD, 2003, p. CThPDA9.

103 S. Y. Set, H. Yaguchi, Y. Tanaka and M. Jablonski, J. Lightwave Technol., 2004, 22, 51-56.

104 S. Yamashita, Y. Inoue, S. Maruyama, Y. Murakami, H. Yaguchi, M. Jablonski and S. Y. Set, Opt. Lett., 2004, 29, 1581-1583.

105 S. Yamashita, Y. Inoue, K. Hsu, T. Kotake, H. Yaguchi, D. Tanaka, M. Jablonski and S. Y. Set, IEEE Photonics Technol. Lett., 2005, 17, $750-752$.

106 Y. W. Song, S. Y. Set, S. Yamashita, C. S. Goh and T. Kotake, IEEE Photonics Technol. Lett., 2005, 17, 1623-1625.
107 C. S. Goh, K. Kikuchi, S. Y. Set, D. Tanaka, T. Kotake, M. Jablonski, S. Yamashita and T. Kobayashi, in Conference on Lasers and Electro-Optics (CLEO), Baltimore, MD, 2005, pp. 1644-1646.

108 M. Nakazawa, S. Nakahara, T. Hirooka and M. Yoshida, Opt. Lett., 2006, 31, 915-917.

109 A. G. Rozhin, Y. Sakakibara, S. Namiki, M. Tokumoto, H. Kataura and Y. Achiba, Appl. Phys. Lett., 2006, 88, 051118.

110 G. Della Valle, R. Osellame, G. Galzerano, N. Chiodo, G. Cerullo, P. Laporta and O. Svelto, Appl. Phys. Lett., 2006, 89, 231115.

111 S. Yamashita, Y. Inoue, S. Maruyama, Y. Murakami, H. Yaguchi, T. Kotake and S. Y. Set, Jpn. J. Appl. Phys., 2006, 45, L17-L19.

112 Y. W. Song, S. Yamashita, C. S. Goh and S. Y. Set, Opt. Lett., 2007, 32, $148-150$.

113 Y. W. Song, S. Yamashita, C. S. Goh and S. Y. Set, Opt. Lett., 2007, 32, 430-432.

114 Y. W. Song, S. Yamashita, E. Einarsson and S. Maruyama, Opt. Lett., 2007, 32, 1399-1401.

115 K. Kieu and M. Mansuripur, Opt. Lett., 2007, 32, 2242-2244.

116 J. W. Nicholson, R. S. Windeler and D. J. DiGiovanni, Opt. Express, 2007, 15, 9176-9183.

117 A. V. Tausenev, E. D. Obraztsova, A. S. Lobach, A. I. Chernov, V. I. Konov, A. V. Konyashchenko, P. G. Kryukov and E. M. Dianov, Quantum Electron., 2007, 37, 205-208.

118 Y. W. Song, K. Morimune, S. Y. Set and S. Yamashita, Appl. Phys. Lett., 2007, 90, 021101.

119 A. V. Tausenev, E. D. Obraztsova, A. S. Lobach, V. I. Konov, A. V. Konyashchenko, P. G. Kryukov and E. M. Dianov, Quantum Electron., 2007, 37, 847-852.

120 K. Kieu and M. Mansuripur, Opt. Lett., 2008, 33, 64-66.

121 M. A. Solodyankin, E. D. Obraztsova, A. S. Lobach, A. L. Chernov, A. V. Tausenev, V. I. Konov and E. M. Dianov, Opt. Lett., 2008, 33, $1336-1338$

122 N. Nishizawa, Y. Seno, K. Sumimura, Y. Sakakibara, E. Itoga, H. Kataura and K. Itoh, Opt. Express, 2008, 16, 9429-9435.

123 K. Kieu and F. W. Wise, Opt. Express, 2008, 16, 11453-11458.

124 A. Martinez, S. Uchida, Y. W. Song, T. Ishigure and S. Yamashita, Opt. Express, 2008, 16, 11337-11343.

125 A. Martinez, K. M. Zhou, I. Bennion and S. Yamashita, Opt. Express, 2008, 16, 15425-15430.

126 F. Wang, A. G. Rozhin, Z. Sun, V. Scardaci, I. H. White and A. C. Ferrari, Phys. Status Solidi B, 2008, 245, 2319-2322.

127 Y. W. Song, S. Yamashita and S. Maruyama, Appl. Phys. Lett., 2008, 92, 021115.

128 Z. Sun, A. G. Rozhin, F. Wang, V. Scardaci, W. I. Milne, I. H. White, F. Hennrich and A. C. Ferrari, Appl. Phys. Lett., 2008, 93, 061114.

129 A. V. Tausenev, E. D. Obraztsova, A. S. Lobach, A. I. Chernov, V. I. Konov, P. G. Kryukov, A. V. Konyashchenko and E. M. Dianov, Appl. Phys. Lett., 2008, 92, 171113.

130 F. Shohda, T. Shirato, M. Nakazawa, K. Komatsu and T. Kaino, Opt. Express, 2008, 16, 21191-21198.

131 Q. Wang, K. Khanh, S. Honkanen and F. Kueppers, in Conference on Silicon Photonics and Photonic Integrated Circuits, ed. G. C. Righini, S. K. Honkanen, L. Pavesi and L. Vivien, Strasbourg, France, 2008, p. A9961.

132 H. Chen and Q. Wang, in Conference on Solid State Lasers and Amplifiers III, ed. J. A. Terry, T. Graf and H. Jelinkova, Strasbourg, France, 2008, p. S9981.

133 J. W. Nicholson and D. J. DiGiovanni, IEEE Photonics Technol. Lett., 2008, 20, 2123-2125.

134 S. Kivisto, T. Hakulinen, A. Kaskela, B. Aitchison, D. P. Brown, A. G. Nasibulin, E. I. Kauppinen, A. Harkonen and O. G. Okhotnikov, Opt. Express, 2009, 17, 2358-2363.

135 N. N. Il'ichev, E. D. Obraztsova, S. V. Garnov and S. E. Mosaleva, Quantum Electron., 2004, 34, 572-574.

136 N. N. Il'ichev, E. D. Obraztsova, P. P. Pashinin, V. I. Konov and S. V. Garnov, Quantum Electron., 2004, 34, 785-786.

137 T. R. Schibli, K. Minoshima, H. Kataura, E. Itoga, N. Minami, S. Kazaoui, K. Miyashita, M. Tokumoto and Y. Sakakibara, Opt. Express, 2005, 13, 8025-8031.

138 N. N. Il'ichev, S. V. Garnov and E. D. Obraztsova, in 19th International Winterschool and Euroconference on Electronic Properties of Novel Materials, ed. H. Kuzmany, J. Fink, M. Mehring and S. Roth, Kirchberg, Austria, 2005, pp. 611-615. 
139 K. H. Fong, K. Kikuchi, C. S. Goh, S. Y. Set, R. Grange, M. Haiml, A. Schlatter and U. Keller, Opt. Lett., 2007, 32, 38-40.

140 S. V. Garnov, S. A. Solokhin, E. D. Obraztsova, A. S. Lobach, P. A. Obraztsov, A. L. Chernov, V. V. Bukin, A. A. Sirotkin, Y. D. Zagumennyi, Y. D. Zavartsev, S. A. Kutovoi and I. A. Shcherbakov, Laser Phys. Lett., 2007, 4, 648-651.

141 A. Schmidt, S. Rivier, G. Steinmeyer, J. H. Yim, W. B. Cho, S. Lee, F. Rotermund, M. C. Pujol, X. Mateos, M. Aguilo, F. Diaz, V. Petrov and U. Griebner, Opt. Lett., 2008, 33, 729-731.

142 W. B. Cho, J. H. Yim, S. Y. Choi, S. Lee, U. Griebner, V. Petrov and F. Rotermund, Opt. Lett., 2008, 33, 2449-2451.

143 J. H. Yim, W. B. Cho, S. Lee, Y. H. Ahn, K. Kim, H. Lim, G. Steinmeyer, V. Petrov, U. Griebner and F. Rotermund, Appl. Phys. Lett., 2008, 93, 161106.

144 S. H. Lim, H. I. Elim, X. Y. Gao, A. T. S. Wee, W. Ji, J. Y. Lee and J. Lin, Phys. Rev. B: Condens. Matter Mater. Phys., 2006, 73, 045402 .
145 Y. W. Zhu, H. I. Elim, Y. L. Foo, T. Yu, Y. J. Liu, W. Ji, J. Y. Lee, Z. X. Shen, A. T. S. Wee, J. T. L. Thong and C. H. Sow, Adv. Mater., 2006, 18, 587-592.

146 W. Ji and H. I. Elim, in Conference on Optoelectronic Materials and Devices, ed. Y. H. Lee, F. Koyama and Y. Luo, Spie-Int Soc Optical Engineering, Gwangju, South Korea, 2006, pp. U1067-U1074.

147 A. A. Onushchenko, A. A. Zhilin, G. T. Petrovskii, E. L. Raaben, M. S. Gaponenko, A. M. Malyarevich, K. V. Yumashev and V. V. Golubkov, J. Opt. Technol., 2006, 73, 576-583.

148 A. A. Sirotkin, L. Di Labio, A. I. Zagumennyi, Y. D. Zavartsev, S. A. Kutovoi, V. I. Vlasov, W. Luthy, T. Feurer, A. A. Onushchenko and I. A. Shcherbakov, Appl. Phys. B: Lasers Opt., 2009, 94, 375-379.

149 H. I. Elim, W. Ji, M. T. Ng and J. J. Vittal, Appl. Phys. Lett., 2007, 90, 033106 .

150 X. Y. Hu, P. Jiang, C. Xin, H. Yang and Q. H. Gong, Appl. Phys. Lett., 2009, 94, 031103. 